\title{
A numerical study on offshore wind turbines embedded in sands
}

Behrang Pedram BSc, MSc, MEng, PhD

Scientist, School of Civil Engineering, University of Western Australia,

Crawley, WA 6009, Australia

This paper compares the ultimate lateral capacity and stiffness of circular and square pile-towers embedded in two different sand deposits. The benefits of square pile-towers with respect to circular structures are brought out in this paper through a parametric study conducted by three dimensional finite element analyses. In the numerical models, the pile-towers are treated as an elastoplastic material while the soil is idealised using the Drucker-Prager constitutive model with a linearly increasing soil modulus. The effects of pile diameter, pile thickness, eccentricity and pile length for free-head pile-towers embedded in both sand deposits are investigated. The results illustrate that the stiffness and ultimate lateral capacity of a square pile-tower are substantially greater than a circular structure. Furthermore, the soil displacements and stresses at the ultimate capacity when a square pile-tower is adopted instead of circular structure are not considerable. The ultimate lateral capacities from the numerical models for both pile-tower configurations are compared with the usual techniques available in the literature, and the most suitable methods for these structures are illustrated, while the method adopted by Zhang et al. is ruled out.

\section{Notation}

$a \quad$ location of the pivot point $[L]$

$B \quad$ pile breadth for square piles $[L]$

c cohesion $\left[F L^{-2}\right]$

$d \quad$ parameter related to cohesion

$D_{\mathrm{p}} \quad$ pile diameter for circular piles $[L]$

e eccentricity or tower length $[L]$

$E_{\mathrm{p}} \quad$ modulus of elasticity of pile $\left[F L^{-2}\right]$

$E_{\mathrm{p}} I_{\mathrm{p}} \quad$ flexural rigidity $\left[F L^{2}\right]$

$E_{\mathrm{s}} \quad$ soil modulus of elasticity $\left[F L^{-2}\right]$

$f \quad$ location of the maximum moment on the pile $[L]$

$G \quad$ shear modulus $\left[F L^{-2}\right]$

$G^{*} \quad$ equivalent shear modulus $\left[F L^{-2}\right]$

$H_{\mathrm{u}} \quad$ ultimate lateral capacity of pile $[F]$

$I_{\mathrm{p}} \quad$ moment of inertia of pile $\left[L^{4}\right]$

$J \quad$ Drucker-Prager parameter related to the deviatoric stress $\left[F L^{-2}\right]$

$K \quad$ lateral earth pressure coefficient, related to the method of pile installation

$k \quad$ ratio of yield stresses

$K_{0} \quad$ lateral earth pressure coefficient at rest

$K_{\mathrm{p}} \quad$ coefficient of passive earth pressure

$L_{\mathrm{e}} \quad$ effective length of the pile $[L]$

$L_{\mathrm{p}} \quad$ pile length underground $[L]$

$M_{\max }$ maximum moment generated on pile section [FL]

$M_{\text {yield }}$ yield moment of pile section [FL]

$p \quad$ mean stress $\left[F L^{-2}\right]$

$P_{\mathrm{u}} \quad$ ultimate lateral resistance of sand $\left[F L^{-1}\right]$

$t \quad$ pile thickness $[L]$

$\mathrm{Z} \quad$ depth under the ground $[L]$ $\beta \quad$ Drucker-Prager parameter related to the friction angle

$\gamma^{\prime} \quad$ effective unit weight of sand $\left[F L^{-3}\right]$

$\delta \quad$ interface friction angle between pile and the soil

$\eta \quad$ shape factor for earth pressure in front of the pile

$\xi \quad$ shape factor for lateral shear drag

$\sigma_{\mathrm{v}}{ }^{\prime} \quad$ effective vertical overburden pressure of sand $\left[F L^{-2}\right]$

$v \quad$ Poisson's ratio

$\phi^{\prime} \quad$ effective friction angle of sand (degrees)

\section{Introduction}

Single hollow steel pile-towers are extensively used around the world to support offshore wind turbines. These structures are under complex combined foundation loads, which are generated by the weight of the structure coupled with environmental loadings. These pile structures (monopiles) are generally under low vertical loads but high lateral forces. Figure 1 shows a schematic illustration of an offshore pile-tower structure.

Several methods are proposed for predicting the ultimate lateral capacity of monopiles in cohesionless material (Broms, 1964; Fleming et al., 2009; Meyerhof et al., 1981, 1988; Prasad and Chari, 1999; Zhang et al., 2005). Furthermore, many researchers concentrate on the so-called stiffness of pile structures and their bending moments (Davies and Budhu, 1986; Poulos, 1971; Poulos and Davis, 1980).

Davies and Budhu (1986) provide Equation 1 for calculating the effective length of a pile structure, which is embedded in a constant soil modulus. In Equation 1, $E_{\mathrm{p}}$ is the modulus of elasticity of the pile, $D_{\mathrm{p}}$ is the pile diameter and $E_{\mathrm{s}}$ is the soil modulus. If the pile's 
A numerical study on offshore wind

turbines embedded in sands

Pedram

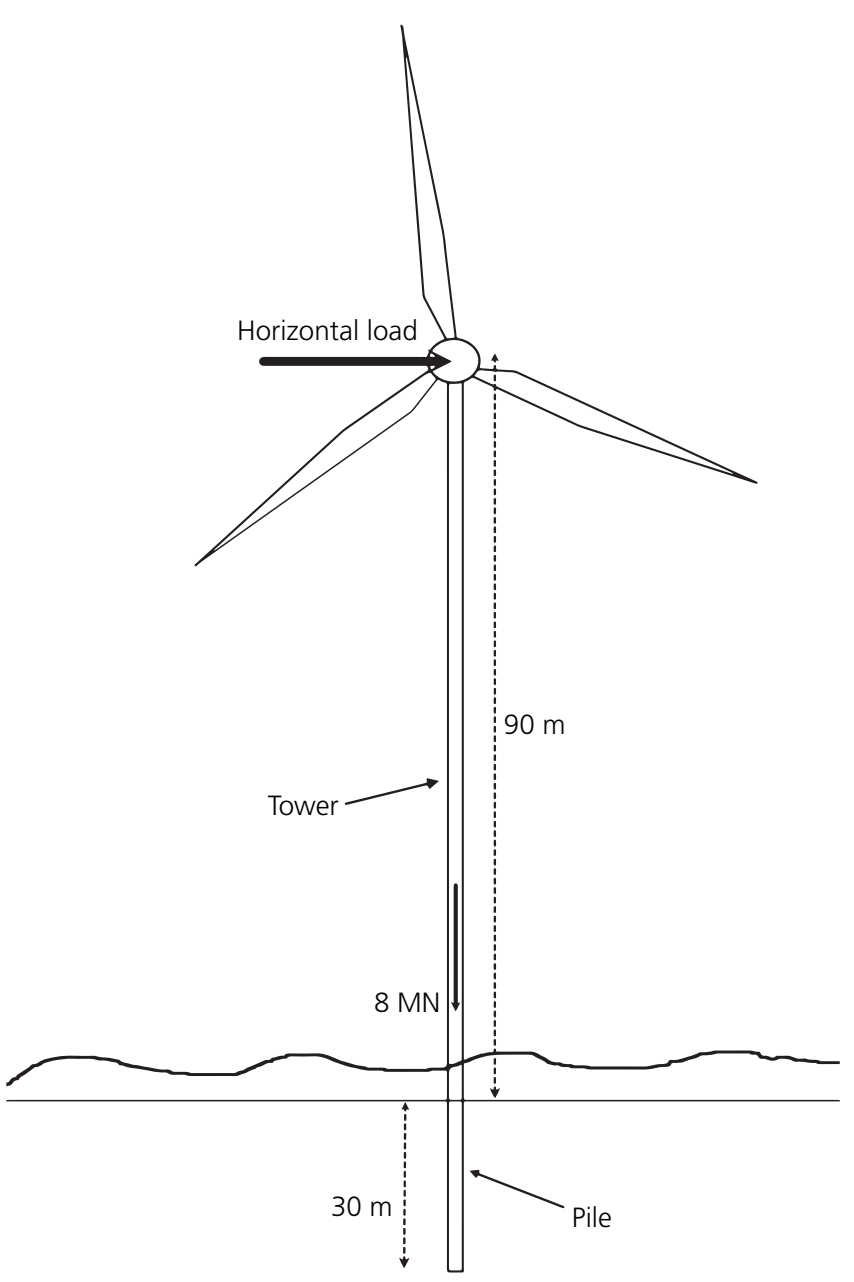

Figure 1. Schematic illustration of an offshore pile-tower structure (not to scale)

length is greater than $L_{\mathrm{e}}$, the lateral deflection is one-thousandth of the head deflection, and consequently, the stiffness of the pile structure does not change by further increasing its length. Equation 1 is derived for a solid circular section for sections other than this; an equivalent value of $E_{\mathrm{p}}$ is calculated through equating the flexural rigidity $\left(E_{\mathrm{p}} I_{\mathrm{p}}, I_{\mathrm{p}}\right.$ is the moment of inertia of the solid pile section) of the structures. Furthermore, for a square pile structure, the width is equal to the diameter of the circular pile.

1.

$$
L_{\mathrm{e}}=0.5 D_{\mathrm{p}}\left(\frac{E_{\mathrm{p}}}{E_{\mathrm{s}}}\right)^{0.36}
$$

Meyerhof (1995) provides Equation 2 from Poulos and Davis (1980) and mentions that a pile is considered flexible if the value of $K_{\mathrm{r}}$ is less than $0 \cdot 01$. In Equation 2, $E_{\mathrm{p}} I_{\mathrm{p}}$ is the flexural rigidity of the pile, and $E_{\mathrm{s}}$ is the average soil modulus or the soil modulus at the pile tip (Prasad and Chari, 1999), and $L_{\mathrm{p}}$ is the pile length under the ground. In Equation 2, the actual values of $E_{\mathrm{p}}$ and $I_{\mathrm{p}}$ of the structure are considered.
2. $K_{\mathrm{r}}=\frac{E_{\mathrm{p}} I_{\mathrm{p}}}{E_{\mathrm{s}} L_{\mathrm{p}}^{4}}$

Carter and Kulhawy (1992) provide Equations 3 and 4 and mention that if the pile length is less than $L_{\mathrm{e}}$ the pile behaves as a rigid member. In Equations 3 and $4, D_{\mathrm{p}}$ is the pile diameter, $v$ is the Poisson's ratio of the soil and $G^{*}$ is the equivalent shear modulus of the soil and $G$ is the soil's shear modulus.

3. $L_{\mathrm{e}} \leq 0.05 D_{\mathrm{p}}\left(\frac{E_{\mathrm{p}}}{G^{*}}\right)^{0.5}$

4. $G^{*}=G\left(1+\frac{3 v}{4}\right)$

Poisson's ratio does not significantly influence the lateral capacity of a pile structure (Poulos and Davis, 1980). To obtain a conservative value of $L_{\mathrm{e}}$, a Poisson value of $0 \cdot 15$ (the range is between $0 \cdot 15$ and $0 \cdot 35$ for loose to dense sands, respectively [Budhu, 2007]) can be inserted into Equation 4, and the value of $G^{*}$ can be directly related to the soil modulus through $G=\frac{E_{\mathrm{s}}}{2(1+v)}$. Equation 5 provides the most conservative value of $L_{\mathrm{e}}$ for sands (for dense sands, the value of 0.071 in Equation 5 is changed to $0 \cdot 073$ ).

5. $\quad L_{\mathrm{e}} \leq 0.071 D_{\mathrm{p}}\left(\frac{E_{\mathrm{p}}}{E_{\mathrm{s}}}\right)^{0.5}$

As discussed by Broms (1964), long piles generate moments higher than the yield moment of the pile material $\left(M_{\text {yield }}\right)$, while for short piles the soil failure controls the ultimate lateral capacity of the pile structure. For a long pile under the definition of Broms (1964), the constructive material significantly influences the ultimate lateral capacity, while for a short pile the ultimate capacity is controlled by the surrounding soil, which is usually related to the soil's friction angle.

The concept of a flexible pile with respect to its stiffness (Equation 1) should be differentiated from the notion adopted by Broms (1964). To differentiate these two criteria, the word long is used when the pile material fails (Broms, 1964), and flexible is used for the concept of pile stiffness hereafter.

The stiffness and ultimate lateral capacity of hollow circular and square monopile structures embedded in two different soil groups are investigated by 3D finite element (FE) analyses. As discussed by Reese and Van Impe (2011), 'most of the case studies and tests have been performed with piles with circular cross sections', and therefore, insufficient data are available for square pile structures. This gap of data for square pile structures implies that rough 
and crude estimates for such piles are used when comparing the behaviour of circular and square piles by the usual methods available in the literature. This problem is due to the higher side shear resistance that square piles illustrate. Consequently, their stiffness is higher than that of a circular pile with the same volume of material. One of the aims of this paper is to decrease the gap in knowledge between these two pile configurations for large pile diameters embedded in sands.

The numerical models in this paper are similar to the models used for Lehane et al. (2014), which investigated the behaviour of piled footing structures embedded in sands. Those numerical models captured the stiffness and the ultimate lateral capacity of the centrifugal tests accurately.

\section{Methodology}

The 3D FE analyses were carried out by ABAQUS V6.7 from Dassault Systèmes (HKS, 2006). The paper investigates the influence of pile thickness, pile diameter, eccentricity and pile length for two different pile configurations.

\section{Pile-soil details}

The monopiles in the numerical models were modelled as an elastoplastic material, and the soil was idealised using the linear Drucker-Prager perfectly plastic constitutive model with a linearly increasing modulus of elasticity. The yield surface for this soil model has the form of $F=J-p \tan (\beta)-d=0$, in which $p$ is the mean stress $\left[\left(\sigma_{1}-2 \sigma_{3}\right) / 3\right], J$ is related to the deviatoric stress $\left(\sigma_{1}-\sigma_{3} / k\right.$, where $k$ is the ratio of the yield stress in tension to the yield stress in compression, and is equal to $\left.3-\sin \phi^{\prime} / 3+\sin \phi^{\prime}\right), \beta$ is the slope of the yield surface in the $p-J$ stress plane $\left(\tan \beta=6 \sin \phi^{\prime} / 3-\sin \phi^{\prime}\right)$ and $d$ is the cohesion of the material.

The pile-towers were all constructed out of steel, and the original outer diameter of the hollow circular pile-tower was equal to $4.6 \mathrm{~m}$, its thickness was $60 \mathrm{~mm}$ and it had an eccentricity of $90 \mathrm{~m}$. The original design of the hollow square pile-tower had an outer breadth of $4.6 \mathrm{~m}$, a thickness of $47 \mathrm{~mm}$ and an eccentricity value of $90 \mathrm{~m}$. It must be noted that the thicknesses of the hollow circular and square monopiles were adjusted so that their surface areas and consequently their volumes would be equal. This allows the structures to be compared with respect to their stiffness and ultimate lateral capacities. As discussed by Ugural (2007), the optimum design is the best solution to a design problem with given constraints, that is, considering the minimum weight, volume and minimum cost of construction. In regards to this constraint, the moments of inertia are not equated in this paper.

The force generated by the nacelle, hub and rotor acting on top of the towers was equal to $2.5 \mathrm{MN}$, while the water level was assumed $5 \mathrm{~m}$ above the ground level for all numerical models. This meant that for the pile/tower structures, the buoyant unit weight of the metal was considered up to $5 \mathrm{~m}$ above the ground level, while the effective unit weight of the soil was considered in the analyses.

The mechanical properties of the pile-towers for the numerical models are illustrated in Table 1. It must be noted that steel S355 $\mathrm{MC}$ is a ductile material, and its yield strength under tension and compression are equal (Ugural and Fenster, 2003). The yield strength of steel S355 MC is $394 \mathrm{MPa}$, but a value of $355 \mathrm{MPa}$ that is equal to the proportional limit of the metal was considered for the numerical models ( $10 \%$ less than the yield strength). Moreover, the Von Mises yield criterion was adopted for the steel pile-tower structures; this criterion is well suited for isotropic metals.

Two soil types were considered for the numerical models. Table 1 illustrates the mechanical properties adopted for both soil groups. The Poisson's ratios in Table 1 were calculated in terms of the at-rest earth pressure coefficient $K_{0}$ as in the form of $K_{0} / 1+K_{0}$. The value of $K_{0}$ itself was calculated from the effective friction angle of the soil $\left(\phi^{\prime}\right)$, as in $K_{0}=1-\sin \phi^{\prime}$ (Jaky, 1944). The soil modulus for both soils groups was increased linearly from the ground level with the aid of a Python script. As discussed by Poulos and Davis (1980), a linear increase in the soil modulus is relevant for cohesionless soil due to the very high strain levels at shallower depths. To initiate the calculations, a small cohesion $(0.5 \mathrm{kPa})$ was essential for all numerical models.
Loose sand (Group A)

Unit weight: $78 \mathrm{kN} / \mathrm{m}^{3}$

Modulus of elasticity: $200 \mathrm{GPa}$

Poisson's ratio: $0 \cdot 32$

Yield strength: $355 \mathrm{MPa}$
Effective unit weight: $10 \mathrm{kN} / \mathrm{m}^{3}$

Modulus of elasticity: 700Z(m) (kPa)

( $Z$ is the depth under the ground)

Poisson's ratio: 0.33

Dilation angle: $0^{\circ}$

Friction angle: $30^{\circ}$
Dense sand (Group B)

$10 \mathrm{kN} / \mathrm{m}^{3}$
$3500 \mathrm{Z}(\mathrm{m})(\mathrm{kPa})$
( $\mathrm{Z}$ is the depth under the ground)
0.28
$5^{\circ}$
$37^{\circ}$

Table 1. Mechanical properties of the pile and soils used in the numerical models 
As discussed by Bolton (1986), the critical friction angle for most sand deposits is in the range of $27^{\circ}$ to $37^{\circ}$; in addition, Budhu (2007) discusses that for driven piles, similar to offshore wind turbines, a critical friction angle is usually appropriate (in the case of sands, the critical and residual friction angles are the same [Atkinson, 2007]). Moreover, as driving piles in loose sand densify the surrounding soil through the process of hammering, the value of the soil friction angle along the pile shaft can be taken as the mean of the values prior to and subsequent to driving; that is, $\phi^{\prime}=0.75 \phi_{1}^{\prime}+10$, where $\phi_{1}^{\prime}$ is the soil friction angle prior to pile installation (Poulos and Davis, 1980). In regards to these points, the value of $27^{\circ}$ was increased to $30^{\circ}$, while for the dense sand deposit, the value of $37^{\circ}$ was unchanged. It must be pointed out that the results of a linear Drucker-Prager analysis are similar to the results of a Mohr-Coulomb constitutive model for low friction angles.

\section{Steps, interaction and loads}

Three steps were involved in constructing the numerical models. The first step was to apply gravity to the entire model, the second step was to apply the force generated by the hub, nacelle and rotor to the tower head as a pressure and the third step was to displace the tower's head. The displacement imposed as a boundary condition was applied horizontally to the tower's head, as illustrated in Figure 2. Furthermore, two boundary conditions were necessary for the soil block: the first was applied at the base and restricted movement in all directions, while the second boundary condition was imposed on the sidewalls and allowed movement only in the vertical direction.

In all models, the soil body and the pile-tower structures were tied to each other. By tying the parts with each other, any extraneous shear stress that could be generated between the soil and the pile after applying gravity was avoided. This extraneous shear stress is generated due to different material properties between the soil and the pile structure. Tying the pile and soil together assumes a fully rough interface in shear with a fully bounded surface in tension. As discussed by Barton et al. (1983) and Broms (1964), the separation between the pile and the soil is localised to the back of the pile structure, and it is shallow, while the soil in front of the pile structure is susceptible to failure.

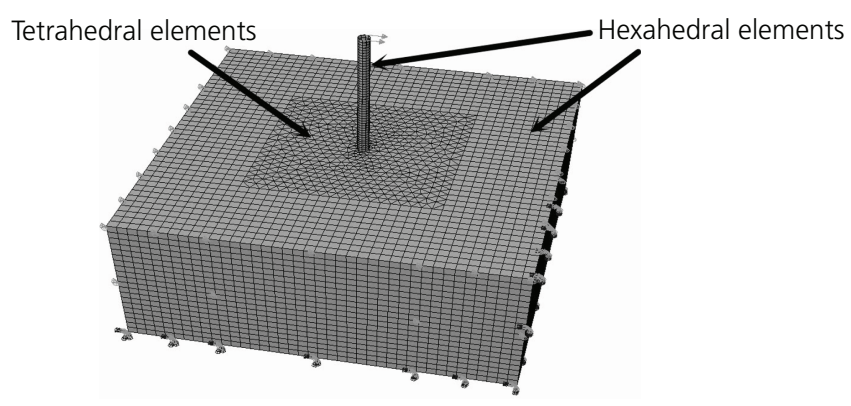

Figure 2. Soil block used for the numerical models with different meshes

\section{Mesh details}

For this study, a square block with dimensions of $200 \times 200 \times 100 \mathrm{~m}$ was constructed so that the displacements and stresses became negligibly small at locations far from the foundation load (Logan et al., 2011). The mesh on the soil body is illustrated in Figure 2. A free meshing technique (using mixed area element shapes) was adopted for the soil block.

The models consisted of linear tetrahedral (4-noded) and hexahedral (8-noded) elements. To overcome the problem with the linear tetrahedral elements (shear locking), in this study, a very fine mesh was adopted for sections that required these elements, as there is no other remedy available (Cook et al., 2002). For the 8-noded brick elements used on the soil and the pile-tower structures, a reduced integration scheme with an hourglass control was considered to decrease the softening effects from the under integration scheme. The number of nodes and elements on the soil block were in the range of 38540 and 82491 , respectively, while the number of nodes and elements on the pile/tower structures were in the range of 992 and 732, respectively.

\section{Parametric studies}

The effects of pile diameter (or breadth), eccentricity, thickness and pile length are investigated for circular and square pile-towers. To illustrate the effects of each parameter, the values were altered individually with respect to the original design which were provided in the section called 'Pile-soil details' for both soil groups. Table 2 illustrates the adopted values for both pile configurations considered in the parametric study.

As the costs of constructing and transporting offshore pile-tower structures can significantly influence the design aspects, when comparing the circular and square structures, it was important that both configurations would generate the same surface areas and volumes (concept of optimum design). With respect to this point, the thicknesses calculated for the circular and square monopiles in each row of Table 2 generate the same volume for both pile-tower configurations.

In regards to Table 2, when a parameter was altered, all other dimensions were unchanged with respect to the original design. For example, the first row of Table 2 is the original design parameters, when the thickness for the hollow circular and square pile-towers change from 60 to $75 \mathrm{~mm}$ and 47 to $58 \cdot 5 \mathrm{~mm}$, respectively, all other dimensions were kept as in the original design. That is, the pile length under the ground $(30 \mathrm{~m})$, the diameter or breadth $(4.6 \mathrm{~m})$ and the eccentricity value $(90 \mathrm{~m})$ were unchanged. By conducting such a parametric study, the influence of each individual parameter on the original design is made clear.

\section{Results and discussion}

\section{The influence of pile-tower thickness}

Figure 3 illustrates the results of the hollow circular pile-towers with different thicknesses embedded in soil groups A. In this figure, the 


\begin{tabular}{|c|c|c|c|c|c|c|c|c|}
\hline \multicolumn{2}{|c|}{ Thickness: mm } & \multirow{2}{*}{$\frac{\text { Diameter: m }}{\text { Circle }}$} & \multirow{2}{*}{$\frac{\text { Breadth: m }}{\text { Square }}$} & \multicolumn{2}{|c|}{ Eccentricity: m } & \multirow{2}{*}{$\frac{\text { Pile length: m }}{\text { Circle and square }}$} & \multirow{2}{*}{$\frac{M_{\text {yield: }} \text { MNm }}{\text { Circle }}$} & \multirow{2}{*}{$\frac{\text { Myield: } \mathrm{MNm}}{\text { Square }}$} \\
\hline Circle & Square & & & Circle & Square & & & \\
\hline 60 & 47 & $4 \cdot 6$ & $4 \cdot 6$ & 90 & 90 & 30 & $340 \cdot 0$ & $456 \cdot 5$ \\
\hline 75 & $58 \cdot 5$ & $5 \cdot 3$ & $5 \cdot 3$ & 120 & 120 & 10 & $421 \cdot 3$ & $563 \cdot 9$ \\
\hline 85 & $66 \cdot 5$ & 6 & 6 & & & 20 & $474 \cdot 3$ & $637 \cdot 7$ \\
\hline 95 & $74 \cdot 5$ & & & & & 45 & $526 \cdot 6$ & $710 \cdot 6$ \\
\hline
\end{tabular}

Table 2. Adopted values for the parametric study

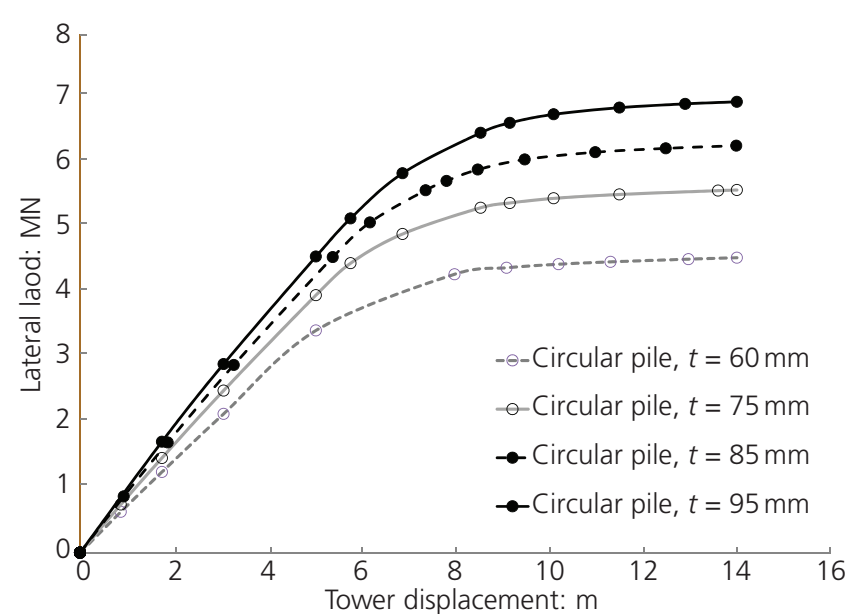

Figure 3. Circular monopiles embedded in soil group A (changes made to pile thickness)

piles have an eccentricity value of $90 \mathrm{~m}$, pile diameters of $4.6 \mathrm{~m}$ and a pile length of $30 \mathrm{~m}$. It is clear that by increasing the pile-tower thickness from 60 to $95 \mathrm{~mm}$, both the ultimate lateral capacity and the stiffness of the structures improve. Figure 4 compares the results from the circular hollow pile-tower structures embedded in soil groups A and B with two different nominated thicknesses. From this figure, it is evident that there are no alterations in the ultimate lateral capacity of each individual structure as the soil parameters change.

Figure 5 compares the results of the hollow circular and square piletower structures with two nominated thicknesses embedded in soil group A. From Figure 5, it is clear that for both thicknesses, the square pile-tower structures illustrate a higher stiffness and ultimate lateral capacity with respect to a circular pile-tower structure with the same amount of material used for constructing both structures. Figure 6 illustrates the Von Mises stresses acting on the circular and square pile-tower structures at their ultimate lateral capacities embedded in soil group A. In Figure 6, the values are a thousand times less than their original values as they were scaled down in the numerical models.

Table 3 illustrates the percentage improvement in stiffness between the two structures embedded in both soil groups at a tower head displacement of $0.23 \mathrm{~m}$. A tower head displacement of $0.23 \mathrm{~m}$

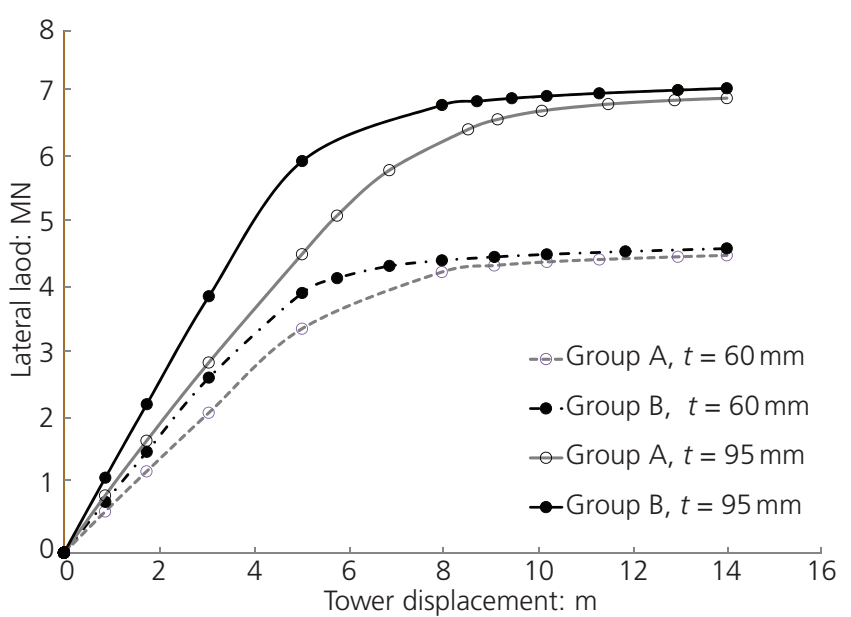

Figure 4. Circular pile-towers with nominated thicknesses embedded in soil groups $A$ and $B$

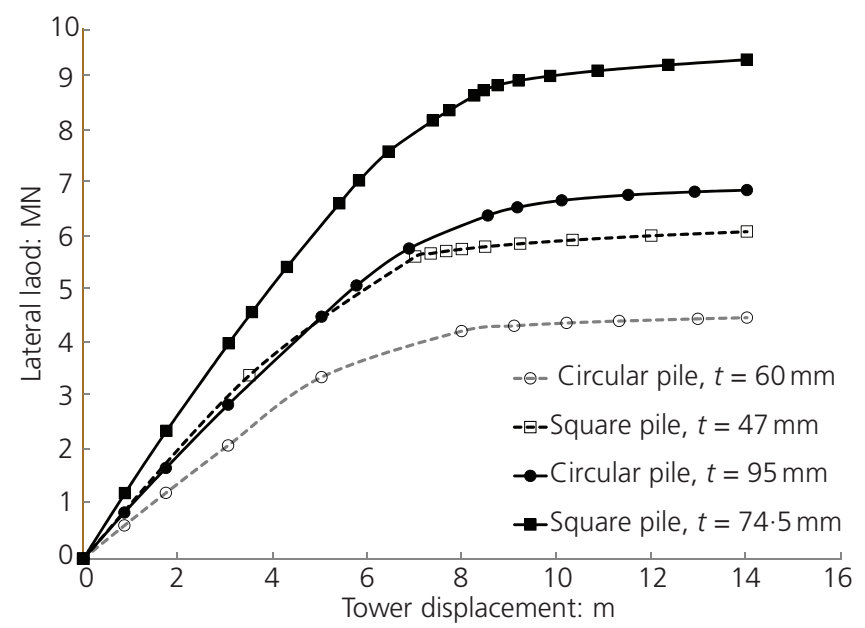

Figure 5. Comparing the results of circular and square pie/towers for nominated thicknesses (soil group A)

equates to $0 \cdot 05 D_{\mathrm{p}}$, where $D_{\mathrm{p}}$ is the original pile diameter $(4.6 \mathrm{~m})$. It is clear that as the thickness increases for each individual structure (circle or square), the difference calculated between the two soil groups does not significantly alter. Furthermore, the 

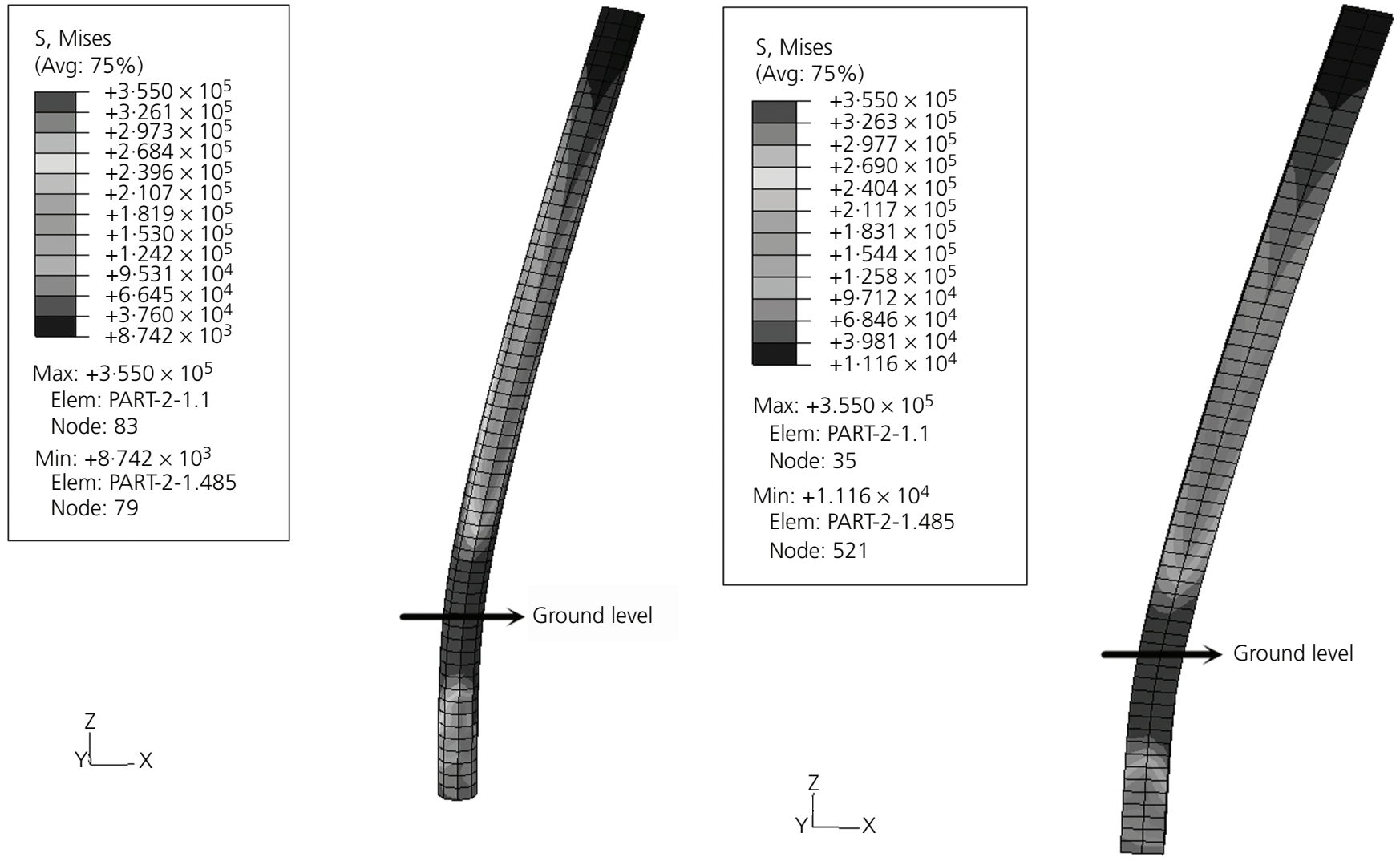

Figure 6. Von Mises stresses acting on the circular (left) and square pile-tower structures (soil group A)

\begin{tabular}{|c|c|c|c|c|c|c|c|c|c|}
\hline \multicolumn{4}{|l|}{ Circle } & \multicolumn{4}{|c|}{ Square } & \multicolumn{2}{|c|}{$\begin{array}{c}\text { \% Difference between } \\
\text { square and circle }\end{array}$} \\
\hline $\begin{array}{l}\text { Thickness: } \\
\mathrm{mm}\end{array}$ & $\begin{array}{l}\text { Group } \\
\text { A:MN }\end{array}$ & $\begin{array}{l}\text { Group } \\
\text { B:MN }\end{array}$ & \%Difference & $\begin{array}{l}\text { Thickness: } \\
\text { mm }\end{array}$ & $\begin{array}{l}\text { Group } \\
\text { A:MN }\end{array}$ & $\begin{array}{l}\text { Group } \\
\text { B:MN }\end{array}$ & \%Difference & Group A & Group B \\
\hline 60 & $0 \cdot 17$ & $0 \cdot 21$ & $+23 \cdot 5$ & 47 & 0.23 & 0.305 & $+32 \cdot 6$ & $+35 \cdot 3$ & $+45 \cdot 23$ \\
\hline 75 & $0 \cdot 2$ & 0.25 & $+25 \cdot 0$ & $58 \cdot 5$ & $0 \cdot 27$ & $0 \cdot 37$ & $+37 \cdot 0$ & $+35 \cdot 0$ & $+48 \cdot 0$ \\
\hline 85 & 0.22 & $0 \cdot 28$ & $+27 \cdot 2$ & $66 \cdot 5$ & 0.293 & $0 \cdot 41$ & $+39 \cdot 9$ & $+33 \cdot 18$ & $+46 \cdot 42$ \\
\hline 95 & 0.23 & 0.305 & $+32 \cdot 6$ & 74.5 & 0.325 & 0.451 & $+38 \cdot 7$ & $+41 \cdot 3$ & $+47 \cdot 86$ \\
\hline
\end{tabular}

Table 3. Comparing the stiffness at $0.05 D_{p}(0.23 \mathrm{~m})$ for different pile-tower thicknesses

percentage improvement calculated between the square and the circular pile-tower configurations is above $+33 \cdot 0 \%$ and $+45 \cdot 0 \%$ for the soft and stiff sand deposits, respectively. If the moments of inertia of the two structures are equated, the square structure will still illustrate a greater stiffness due to the higher shearing resistances along its sides.

Figure 7 illustrates the lateral soil movement in the direction of the applied displacement to the tower head for the circular and square pile-towers embedded in both soil groups. Two nominated thicknesses were considered for comparison purposes; the lateral soil displacements were extracted at a tower head displacement of $0.46 \mathrm{~m}\left(0 \cdot 1 D_{\mathrm{p}}\right)$ for both soil groups. It is clear that the square pile imposes slightly higher displacements on the surrounding soil compared to a circular structure. It is also evident that the pile shapes do not affect the depths of rotation for the two adopted pile configurations. The lateral soil displacements were extracted along the pile shaft at the midpoint of the pile cross-sections. 


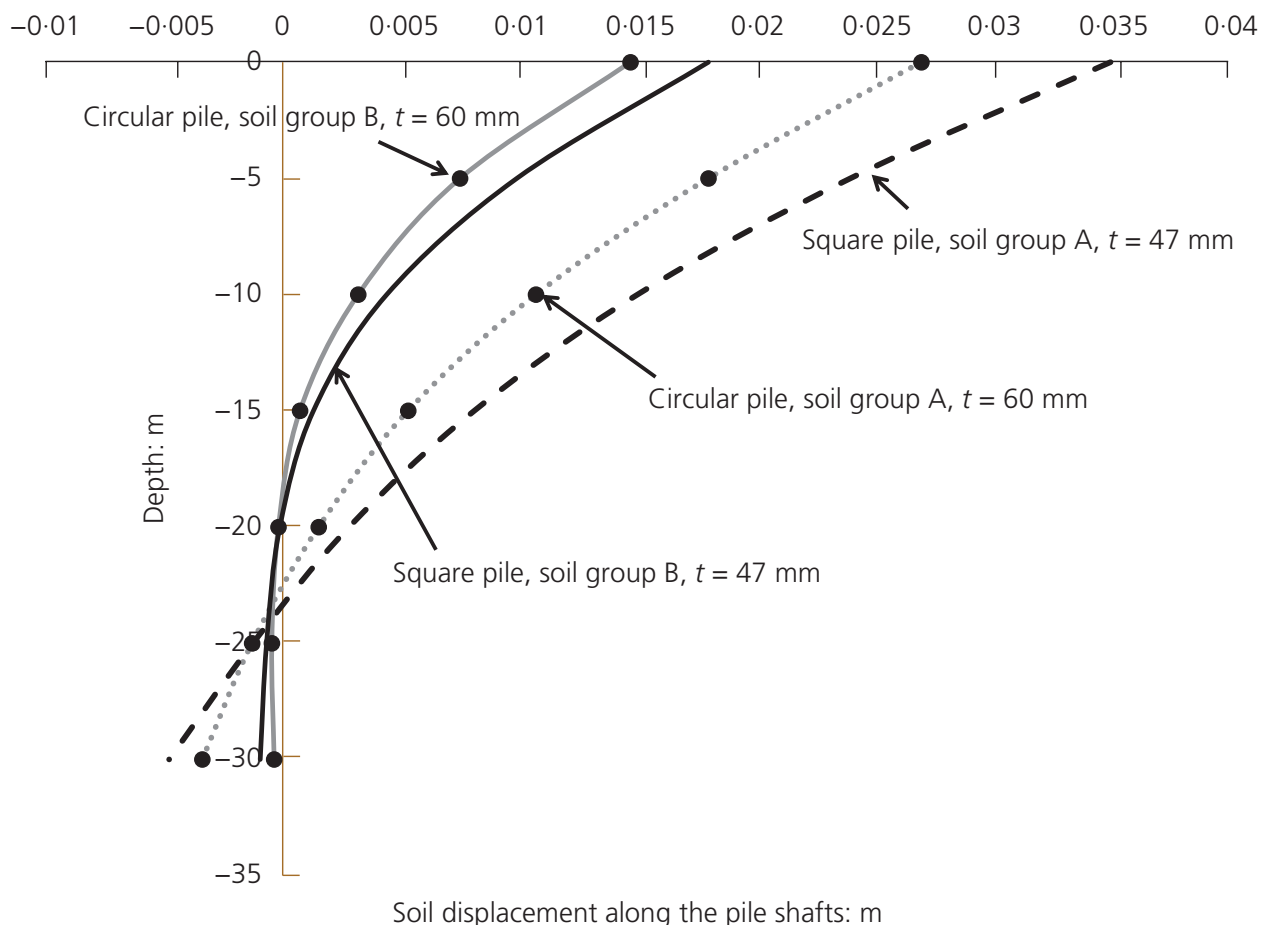

Figure 7. Lateral soil displacements along the circular and square pile-towers (tower head displacement of $0.46 \mathrm{~m}$ )

To check the validity of Broms (1964) criterion, the yield point of the circular and square pile-towers in the numerical models was removed, and the tower heads were laterally displaced. Figure 8 compares the results of this analysis for the thickest circular and square monopiles embedded in soil group A with the results of the monopile structures with an elastoplastic material. It is clear that the pile structures embedded in the soft soil medium fail prior to

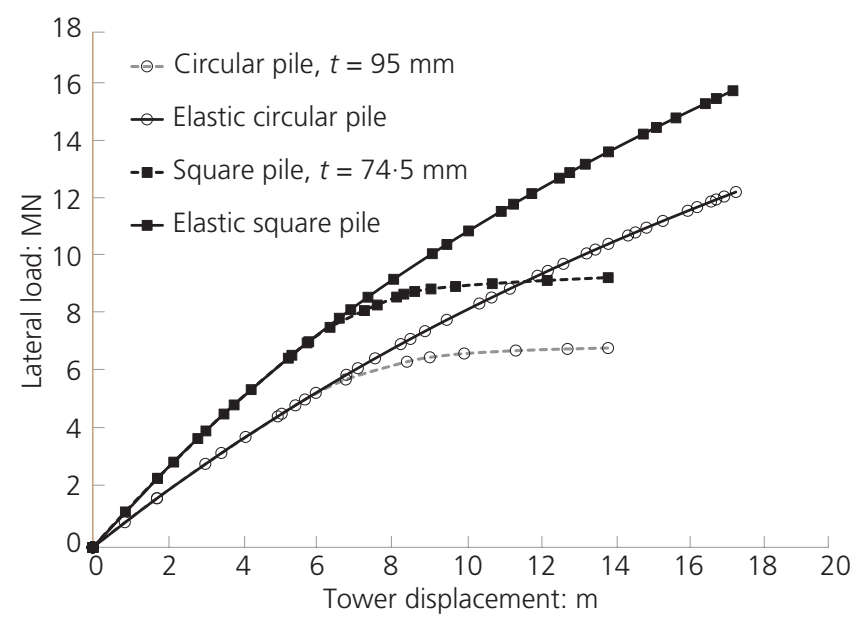

Figure 8. Elastic and elastoplastic circular and square monopiles embedded in soil group $A$ the soil, and so the ultimate lateral capacities are controlled by the pile-tower's structural capacity.

Figure 9 illustrates the stresses $\left(\sigma_{\mathrm{xx}}, \mathrm{x}\right.$ is illustrated in Figure 6) along the pile shaft for the circular and square monopiles embedded in soil group B at a tower head displacement of $10 \mathrm{~m}$. In Figure 9, the thicknesses of the circular and square monopiles are equal to 60 and $47 \mathrm{~mm}$, respectively. It is clear that the stresses at the back of the circular pile cross-section are higher than of a square pile; this is also the case for the soft soil medium (not illustrated). It must be remembered that the points were picked along the mid-section of the circular and square configurations in the direction of the applied load, that is, the location of the highest stresses, as discussed by Prasad and Chari (1999) (compression is positive in Figure 9).

\section{Calculating the ultimate lateral capacities}

The methods adopted by Broms (1964) and Fleming et al. (2009) are considered for comparison purposes with the FE results. Furthermore, the method generated by Zhang et al. (2005) is not employed as the soil was nowhere close to failure (Figure 8). Zhang et al. (2005) takes account of the soil failure for both flexible and rigid piles embedded in cohesionless soils. In their conclusions, they mention 'Because the proposed method considers the ultimate resistance of the soil (not of the pile), it applies to both flexible and rigid piles'.

The value of $a$, the location of the pivot point in Equation 6 that is adopted by Zhang et al. (2005), is used in Equation 7 for calculating the ultimate lateral capacity of a pile structure. In Equation $6, L_{\mathrm{p}}$ is 


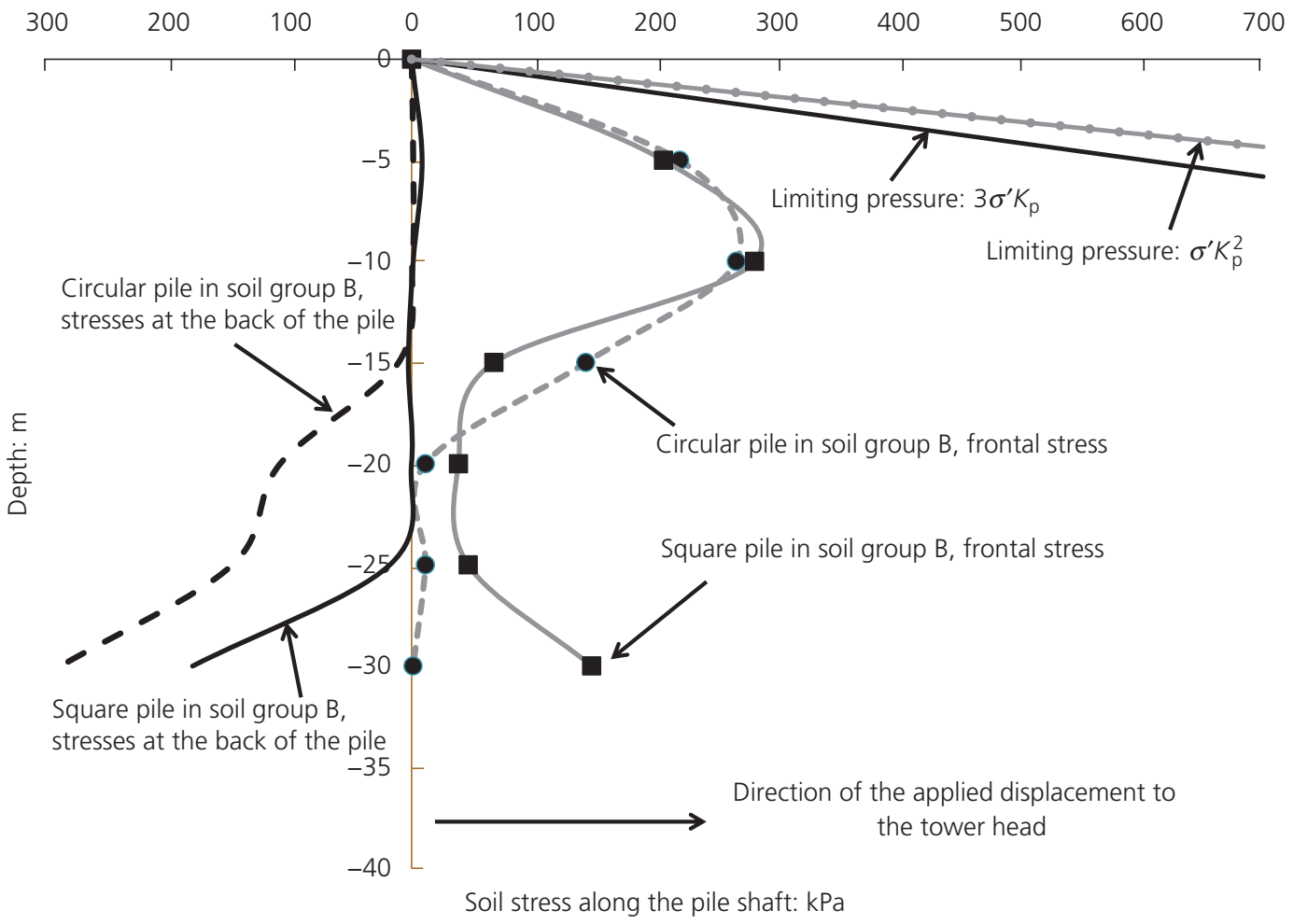

Figure 9. Lateral stresses along the pile shaft for soil group B

(tower head displacement of $10 \mathrm{~m}$ )

the pile length under the ground and $e$ is the eccentricity. In Equation $7, \eta, \xi, K, \delta, \gamma, a, K_{\mathrm{p}}, D_{\mathrm{p}}$ and $H_{\mathrm{u}}$ are the shape factor for non-uniform frontal earth pressure, shape factor to account for lateral shear drag, lateral earth pressure related to the pile type, interface friction angle between pile and soil, soil unit weight, location of the pile's pivot point, passive earth pressure, pile diameter and ultimate lateral capacity, respectively. It is clear that as the pile length grows, the ultimate lateral capacity of the structure increases indefinitely. This is in contradiction with the concept of a long pile structure, where the ultimate lateral capacity is controlled by structural failure.

$$
a=\left[-\left(0 \cdot 56 L_{\mathrm{p}}+2 \cdot 7 e\right)+\right.
$$

6.

$$
\left.\left(5 \cdot 307 L_{\mathrm{p}}^{2}+7 \cdot 29 e^{2}+10 \cdot 541 e L_{\mathrm{p}}\right)^{0.5}\right] / 2 \cdot 1996
$$

7. $H_{\mathrm{u}}=0 \cdot 3\left(\eta K_{\mathrm{p}}^{2}+\xi K \tan \delta\right) \gamma a D_{\mathrm{p}}\left(2 \cdot 7 a-1 \cdot 7 L_{\mathrm{p}}\right)$

Equation 6 adopted by Zhang et al. (2005) is the exact equation developed by Prasad and Chari (1999) for defining the pivot point for a rigid pile structure and should not be used for flexible piles unless its credibility is illustrated. As mentioned by Prasad and Chari (1999) in their conclusions, their method 'should be applied to short rigid piles in uniform cohesionless soils only', and unfortunately, at no point did Zhang et al. (2005) illustrate the credibility of this equation for flexible piles embedded in sands. For flexible piles, the location of the pivot point can significantly alter as the relative density of the soil changes; this point might not significantly influence the results of short piles embedded in sands. As the relative density of the soil increases, the pivot point moves towards the ground level (similar to Figure 7), and this cannot be captured through Equation 6 used by Zhang et al. (2005). Carter and Kulhawy (1992) also provide Equation 8 for defining the location of the pivot point for a short pile, which acts as a rigid body; this equation is for piles that satisfy Equation 5. As mentioned, Equations 6 and 8 are only for short piles and not for flexible pile structures.

8.

$$
\frac{a}{D_{\mathrm{p}}}=\frac{0 \cdot 4\left(\frac{2 L_{\mathrm{p}}}{D_{\mathrm{p}}}\right)^{-1 / 3}+0 \cdot 3 \frac{e}{D_{\mathrm{p}}}\left(\frac{2 L_{\mathrm{p}}}{D_{\mathrm{p}}}\right)^{-7 / 8}}{0 \cdot 3\left(\frac{2 L_{\mathrm{p}}}{D_{\mathrm{p}}}\right)^{-7 / 8}+0 \cdot 8\left(\frac{e}{D_{\mathrm{p}}}\right)\left(\frac{2 L_{\mathrm{p}}}{D_{\mathrm{p}}}\right)^{-5 / 3}}
$$

Prasad and Chari (1999) used Equation 2 for defining the pile lengths in their testing programme, which unfortunately does not illustrate whether the piles lengths were short or intermediate (pile lengths in between the range of Equations 1 and 5). If Equation 5 is used in conjunction with the testing procedure described by Prasad and Chari (1999), it can be concluded that their adopted piles were short (not in the range of intermediate lengths). This illustrates that the equation developed by Prasad and Chari (1999) 
must be considered for very short pile structures, and consequently, the location of the pivot might not be significantly affected by the changes made to the soil modulus of elasticity, similar to Equation 8 derived by Carter and Kulhawy (1992).

Zhang et al. (2005) illustrate that their method provides acceptable results compared to the tests conducted by Barton et al. (1983) for flexible piles tested in their centrifugal programme. As previously discussed, the concept of a long pile defined by Broms (1964) and a flexible pile defined by Davies and Budhu (1986) should not be confused. The tests conducted by Barton et al. (1983) were designed to generate soil failure, and so they were short piles with respect to their ultimate lateral capacities, while they were flexible with respect to their stiffness. The tests conducted by Barton et al. (1983) were solid circular tubes constructed from aluminium, which have high $M_{\text {yield }}$ values, and this caused the surrounding soil to reach failure.

The mechanical properties of the aluminium alloy used in the centrifugal tests conducted by Barton et al. (1983) were not defined in the original paper, but the yield strength of most aluminium alloys is greater than $200 \mathrm{MPa}$ (Ugural and Fenster, 2003), which clearly illustrates that the piles were designed to be flexible with respect to their stiffness but to cause soil failure. This point is evident from Figure 2 demonstrated by Barton et al. (1983) in their original paper, which clearly illustrates that the soil reached failure in the centrifugal tests. Zhang et al. (2005) do not consider these points and assume that the soil fails at all times, and so they compare their method with the results of the centrifugal tests carried out by Barton et al. (1983), which were particularly designed to capture soil failure for $p-y$ curves. Due to these points, Figure 6 generated by Zhang et al. (2005) looks reasonably perfect because the piles were short with respect to their ultimate lateral capacity in the tests conducted by Barton et al. (1983). This is not the case for most flexible pile structures in practice. Most flexible piles are either hollow or have a low yield strength compared to the ultimate lateral capacity of their surrounding soil and fail by the bending moments acting on them. Due to these points, the method adopted by Zhang et al. (2005) can significantly overestimate the ultimate lateral capacity of long and flexible piles embedded in sands, as the ultimate resistance of the pile is ignored and it cannot be incorporated into Equation 7. An example is considered in the section called 'Influence of eccentricity and pile length' to illustrate the shortcomings of the method adopted by Zhang et al. (2005).

A MATLAB script was generated, which followed the guidelines proposed by Broms (1964) and Fleming et al. (2009) with different soil resistances. The method adopted by Fleming et al. (2009) is described at this point. This method is similar to the method adopted by Broms (1964), but the force per unit length of the pile increases as $K_{\mathrm{p}}^{2} \sigma_{\mathrm{v}}^{\prime} D_{\mathrm{p}}$ instead of $3 K_{\mathrm{p}} \sigma_{\mathrm{v}}^{\prime} D_{\mathrm{p}}$.

By taking the moments about the pile toe with the force per unit length of the pile to increase as $P_{\mathrm{u}}=K_{\mathrm{p}}^{2} \sigma_{\mathrm{v}}^{\prime} D_{\mathrm{p}}$ (where $K_{\mathrm{p}}$ is the passive earth pressure, $\sigma_{\mathrm{v}}^{\prime}$ is effective vertical stress and $D_{\mathrm{p}}$ is the pile diameter) provides Equation 9. In Equation 9, $H_{\mathrm{u}}$ is the ultimate lateral capacity of the pile, $L_{\mathrm{p}}$ is the pile length, $\gamma^{\prime}$ is the effective unit weight of the soil and $K_{\mathrm{p}}$ is the passive earth pressure $\left[1+\sin \left(\phi^{\prime}\right) /\left(1-\sin \left(\phi^{\prime}\right)\right]\right.$.

$$
\text { 9. } H_{\mathrm{u}}=\frac{0 \cdot 16 K_{\mathrm{p}}^{2} \gamma^{\prime} D_{\mathrm{p}} L_{\mathrm{p}}^{3}}{\left(L_{\mathrm{p}}+e\right)}
$$

The maximum moment occurs at a depth of $f$ below the ground surface where the shear force is equal to zero. The location of the maximum moment can be calculated as in Equation 10.

$$
\text { 10. } f=1 \cdot 41 \sqrt{\frac{H_{\mathrm{u}}}{K_{\mathrm{p}}^{2} \gamma^{\prime} D_{\mathrm{p}}}}
$$

The maximum moment acting on the pile cross-section at a depth of $f$ below the ground level is calculated as in Equation 11 .

$$
\text { 11. } M_{\max }=H_{\mathrm{u}}\left(e+\frac{2}{3} f\right)
$$

If, after use of Equation 9, the value of $H_{\mathrm{u}}$ results in $M_{\max }>M_{\text {yield }}$ (with $M_{\max }$ calculated from Equation 11 and $M_{\text {yield }}$ calculated from the flexure equation), then the pile is long, and the value of $H_{\mathrm{u}}$ is calculated from Equations 10 and 11 with using $M_{\text {yield }}$ instead of $M_{\max }$ in Equation 11. If $M_{\max }<M_{\text {yield, }}$, then the pile is short, and the value of $H_{\mathrm{u}}$ is calculated from Equation 9. Numerical problems can occur when solving for $f$ and $M_{\max }$ by Equations 10 and 11 for complicated distribution of limiting soil resistance. With respect to the limiting lateral pressures provided by Broms (1964) and Barton et al. (1983), no numerical problems occurred. Moreover, as the location of the maximum bending moments for long piles is located above their point of rotation, the stresses acting at the back of the structures can be ignored, and consequently, a linear increase in the soil resistance must provide acceptable results.

As discussed by Fleming et al. (2009) for the range of friction angles in this study, the ultimate lateral capacities calculated by their method and the method adopted by Broms (1964) provided the same results. The values calculated by the MATLAB script were checked with respect to the charts generated by both researchers. It must be noted that the chart provided by Fleming et al. (2009) does not provide the same results as their method for these structures (pile-towers with high eccentricity values), while the calculated values were in very close agreement with the chart produced by Broms (1964) for long piles embedded in sands.

The script could identify whether the piles were long or short, and the location of the maximum bending moments at their ultimate capacities could be calculated (i.e., calculating the ultimate lateral capacity from Equation 11 and inserting the value back into Equation 10 to find the value of $f$ ). 
Table 4 illustrates the ultimate lateral capacity of each structure embedded in soil groups A and B calculated from the FE analyses and the methods adopted by Broms (1964) and Fleming et al. (2009). It is clear that each individual structure (circle or square) embedded in either soil groups has the same ultimate lateral capacities. From Table 4, it is clear that the ultimate lateral capacities calculated by the methods and the FE analysis illustrate that the square piles embedded in each soil group have a higher capacity compared to a circular pile structure embedded in the same soil. It must be noted that for a $30 \mathrm{~m}$ circular and square pile structure, both methods considered the piles as long; that is, the ultimate lateral capacities are controlled by the pile structure and not by the soil. The difference calculated between the ultimate lateral capacities from the FE analysis and the methods adopted for the square and circular monopile configurations with equal surface areas embedded in the same soil groups are over $+33.0 \%$ for all thicknesses. From the results of Table 4 , it is clear that the ultimate lateral capacities calculated by the two researchers for all dimensions are conservative with respect to the FE results. Furthermore, the calculated capacities by the researchers have a difference of less than $+26 \cdot 0 \%$ with the FE results.

From Tables 3 and 4, it is clear that by slightly increasing the thickness of each configuration within a soil group, both the ultimate lateral capacity and the stiffness of the structures are improved. For example, by increasing the thickness of the circular pile-tower from 60 to $95 \mathrm{~mm}$ in soil group A, the ultimate lateral capacity and stiffness improve by $+55 \cdot 55 \%$ and $+40 \cdot 0 \%$, respectively. In recent years, much research has been conducted to increase the stiffness and the ultimate lateral capacity of pile-towers or to act as substitutes for these structures. Some of these designs are hefty and extremely expensive to construct, while changing the shape or thickness of the pile-tower can substantially enhance the behaviour of the structure without significantly increasing the costs of construction or transportation.

The accuracy of the charts produced by the two researchers can be checked with respect to the circular monopile structure embedded in soil group A for a pile diameter of $4.6 \mathrm{~m}$, pile thickness of $60 \mathrm{~mm}$, pile length of $30 \mathrm{~m}, M_{\text {yield }}=340 \cdot 0 \mathrm{MNm}$ and an eccentricity value of $90 \mathrm{~m}$. The chart produced by Broms (1964) provides a value of around $3.5 \mathrm{MN}$, the chart produced by Fleming et al. (2009) calculates a value of $8.7 \mathrm{MN}$ and the script delivered a value of 3.6 MN. The value calculated by Fleming et al. (2009) through their chart is not in line with the calculated values and can significantly overestimate the ultimate lateral capacity of such structures.

\section{Bending moments}

As the ultimate lateral capacities are controlled by the pile-tower structures, it is important to capture the bending moments generated on the hollow circular and square structures embedded in both soil groups. Pile structures are slender members $\left(L_{\mathrm{p}} / D_{\mathrm{p}}>5\right)$ and so their bending moments can be extracted by a beam element embedded at the centre of their cross-section. As the pile-tower structures were hollow and had a yield point, they had to be converted to solid piles with an equivalent modulus of elasticity, and the yield points were also waived for all structures, that is, the pile-towers were changed to solid elastic structures. The equivalent modulus of elasticity was calculated through equating the flexural rigidity of the solid and hollow pile-tower structures. As the ultimate lateral capacity of the structures was known (Table 4), the tower head displacement imposed as a boundary condition was adjusted so that the same amount of bending moment generated at the ground level on the initial structures (pile-tower with yield) would be imposed on the elastic pile-towers. This method was adopted because the yield point of the hollow structures could not be converted for a solid section.

Figure 10 illustrates the bending moments for the circular and square pile-tower structures embedded in soil group A for the initial design dimensions (the results of group B are not presented). The bending moments were extracted from the FE models with the aid of MATLAB and the Python script.

The location of the plastic hinges for each structure embedded in soil group A is illustrated in Figure 10. The location of the maximum

\section{Circle}

\begin{tabular}{|c|c|c|c|c|}
\hline $\begin{array}{l}\text { Thickness: } \\
\mathrm{mm}\end{array}$ & $\begin{array}{c}\text { FE Group } \\
\text { A: MN }\end{array}$ & $\begin{array}{l}\text { Adopted }^{a} \\
\text { methods, soil } \\
\text { Group A: MN }\end{array}$ & $\begin{array}{c}\text { FE Group } \\
\text { B:MN }\end{array}$ & $\begin{array}{l}\text { Adopted } \\
\text { methods, soil } \\
\text { Group B: MN }\end{array}$ \\
\hline
\end{tabular}

\begin{tabular}{|c|c|c|c|c|c|c|c|c|c|}
\hline 60 & $4 \cdot 5$ & 3.6 & 4.5 & 3.6 & 47 & $6 \cdot 1$ & 4.9 & $6 \cdot 1$ & 4.9 \\
\hline 75 & $5 \cdot 6$ & 4.5 & $5 \cdot 6$ & $4 \cdot 5$ & 58.5 & $7 \cdot 5$ & $6 \cdot 0$ & $7 \cdot 5$ & $6 \cdot 0$ \\
\hline 85 & $6 \cdot 2$ & $5 \cdot 1$ & $6 \cdot 2$ & $5 \cdot 1$ & $66 \cdot 5$ & 8.4 & $6 \cdot 8$ & 8.4 & $6 \cdot 8$ \\
\hline 95 & $7 \cdot 0$ & 5.6 & $7 \cdot 0$ & $5 \cdot 6$ & 74.5 & $9 \cdot 4$ & $7 \cdot 6$ & $9 \cdot 4$ & $7 \cdot 6$ \\
\hline
\end{tabular}

a Methods adopted by Broms (1964) and Fleming et al. (2009) provide the same values 


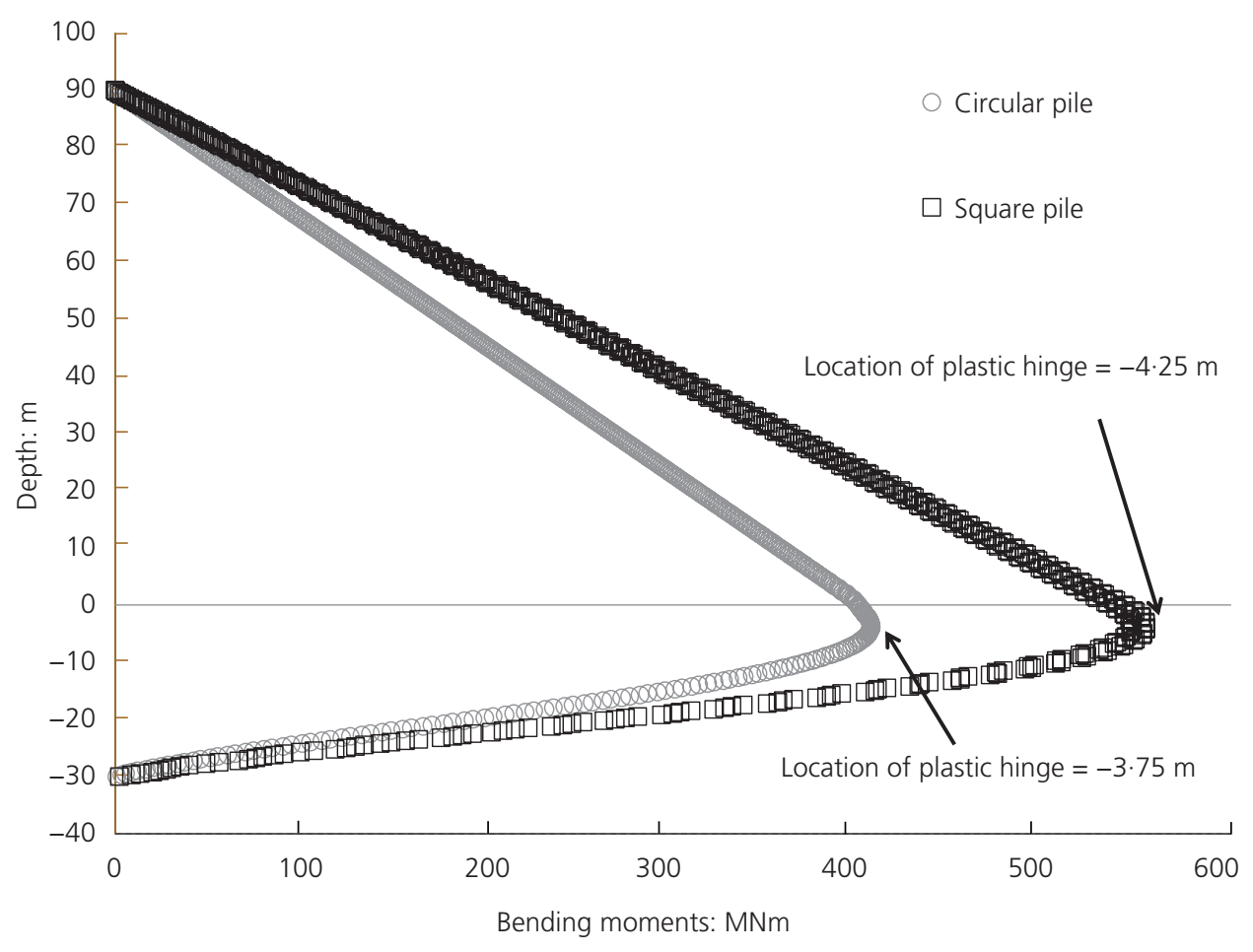

Figure 10. Bending moments generated on the monopile structures embedded in soil group A

bending moments can be checked with respect to the methods adopted by Broms (1964) and Fleming et al. (2009) (section called 'Calculating the ultimate lateral capacities'). For the circular piletower embedded in soil group A, both methods predicted that the maximum bending moment would occur at $-4 \cdot 2 \mathrm{~m}$, and the maximum bending moment calculated by the $\mathrm{FE}$ analysis was at $-3.75 \mathrm{~m}$. For the circular structure embedded in soil group B, Broms' (1964) solution predicted a value of $-3.6 \mathrm{~m}$, the method adopted by Fleming et al. (2009) provided a value of $-3 \cdot 1 \mathrm{~m}$ and the FE analysis calculated a value of $-2 \cdot 6 \mathrm{~m}$. For the square pile-tower embedded in soil group A, the methods adopted by Broms' (1964) and Fleming et al. (2009) both predicted a value of $-4.8 \mathrm{~m}$, while the $\mathrm{FE}$ analysis predicted a depth of $-4 \cdot 25 \mathrm{~m}$. For the square structure embedded in soil group B, Broms (1964) solution predicted a value of $-4.2 \mathrm{~m}$, the method adopted by Fleming et al. (2009) provided a value of $-3.6 \mathrm{~m}$ and the FE analysis calculated a value of $-2 \cdot 9 \mathrm{~m}$.

\section{Influence of the pile-tower diameter}

As the structural capacity controls the ultimate lateral capacities, it is clear that increasing the pile diameter affects the stiffness and the ultimate lateral capacities. Although this is the case, the costs of transporting and pile driving for a very large pile-tower in practice are not an economical option (Malhotra, 2011).

Figure 11 illustrates the results of the hollow circular and square piletower configurations embedded in soil group A with a thickness of 60 and $47 \mathrm{~mm}$, respectively. It is clear that for all adopted diameters and breadths, the square pile-tower illustrates a higher stiffness and ultimate lateral capacity with respect to a circular structure. Table 5 illustrates the percentage improvement between the two structures at a tower head displacement of $0 \cdot 23 \mathrm{~m}$. It is clear that for all cases, by just changing the pile-tower's shape, the stiffness improves by over $+37 \cdot 0 \%$.

Figure 12 demonstrates the soil displacements along the pile crosssections at a tower head displacement of $10 \mathrm{~m}$ for the circular and square configurations embedded in soil group A. It is clear that when the pile diameter increases to $6 \mathrm{~m}$, the soil displacements along the cross-sections at the midpoint of the circular and the square piles are similar, while for a smaller pile diameter, the square pile imposes slightly higher displacements.

Figure 13 illustrates the stresses $\left(\sigma_{\mathrm{xx}}\right)$ in the front and back of the circular pile-towers embedded in soil group A at a tower head displacement of $10 \mathrm{~m}$. In Figure 13, the limiting lateral pressures adopted by Broms (1964) and Barton et al. (1983) are illustrated as well (compression is positive). For small friction angles, the limiting pressures from both methods are equal. It is clear that for a pile diameter of $4.6 \mathrm{~m}$ with a thickness of $60 \mathrm{~mm}$, the frontal stresses are well below the limiting pressures.

Table 6 illustrates the ultimate lateral capacity of the circular and square structures for the changes made to the pile-tower diameters and breadths. It is clear that the ultimate lateral capacities calculated by the adopted methods are conservative with respect to the FE results, and their differences are less than $+27 \cdot 0 \%$. 


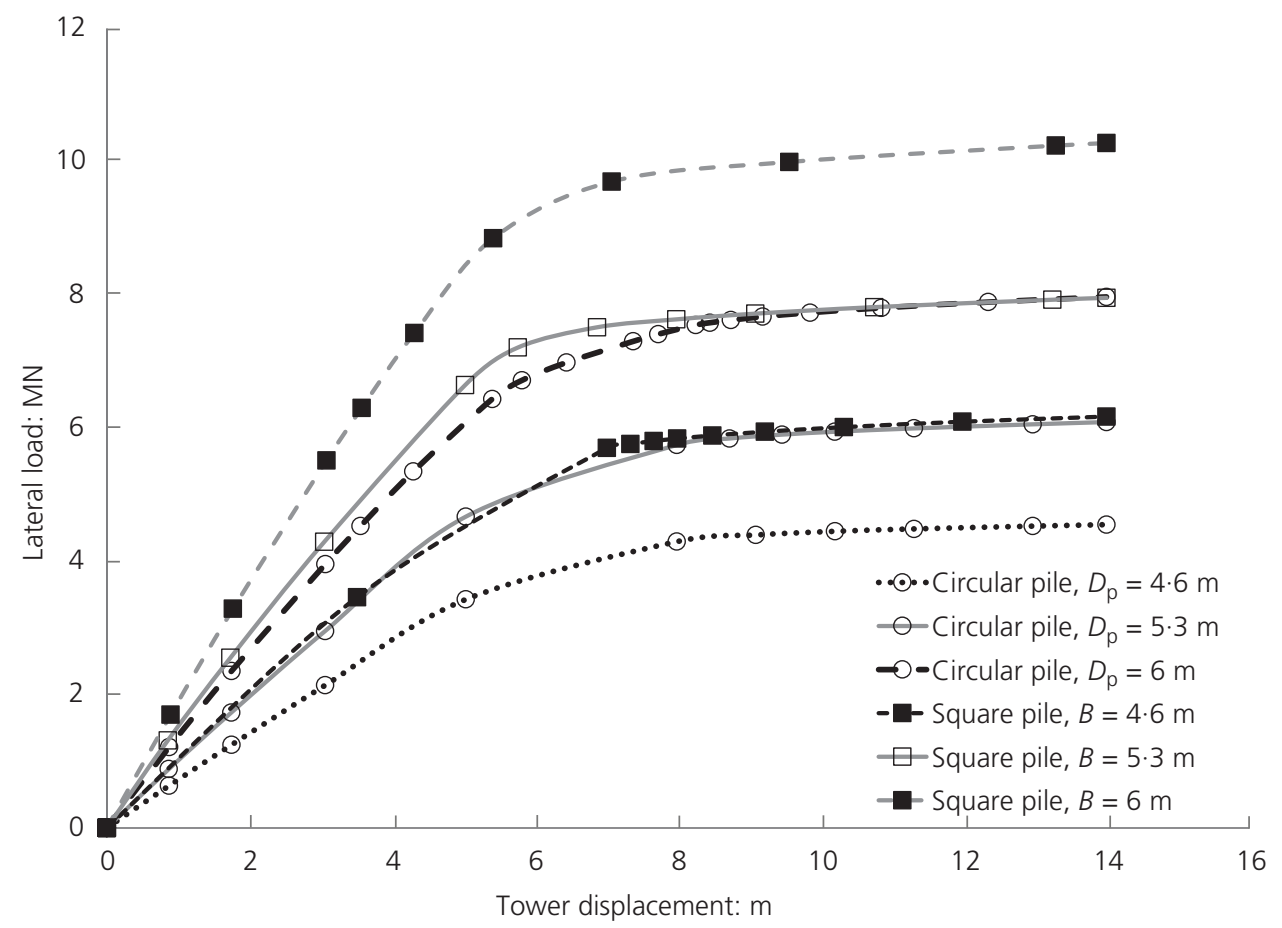

Figure 11. Changes made to the pile-tower diameter and breadth for structures embedded in soil group A

\begin{tabular}{|c|c|c|c|c|c|c|c|c|c|}
\hline \multicolumn{4}{|c|}{ Circle $(t=60 \mathrm{~mm})$} & \multicolumn{4}{|c|}{ Square $(t=47 \mathrm{~mm})$} & \multicolumn{2}{|c|}{$\begin{array}{c}\text { \%Difference between } \\
\text { square and circle }\end{array}$} \\
\hline $\begin{array}{l}\text { Diameter: } \\
\text { m }\end{array}$ & $\begin{array}{l}\text { Group } \\
\text { A:MN }\end{array}$ & $\begin{array}{l}\text { Group } \\
\text { B:MN }\end{array}$ & \%Difference & $\begin{array}{l}\text { Breadth: } \\
\mathrm{m}\end{array}$ & $\begin{array}{l}\text { Group } \\
\text { A:MN }\end{array}$ & $\begin{array}{l}\text { Group } \\
\text { B:MN }\end{array}$ & \%Difference & Group A & Group B \\
\hline $4 \cdot 6$ & $0 \cdot 17$ & $0 \cdot 21$ & $+23 \cdot 5$ & $4 \cdot 6$ & 0.23 & 0.305 & $+32 \cdot 6$ & $+35 \cdot 3$ & $+45 \cdot 2$ \\
\hline $5 \cdot 3$ & 0.23 & 0.28 & $+21 \cdot 73$ & $5 \cdot 3$ & 0.36 & 0.42 & $+16 \cdot 66$ & $+56 \cdot 52$ & $+50 \cdot 0$ \\
\hline 6 & $0 \cdot 32$ & 0.44 & $+37 \cdot 5$ & 6 & 0.44 & 0.645 & $+46 \cdot 5$ & $+37 \cdot 5$ & $+46 \cdot 6$ \\
\hline
\end{tabular}

Table 5. Comparing the stiffness at $0.23 \mathrm{~m}$ for changes made to the pile diameters

Influence of eccentricity and pile length

As illustrated in Table 2, the eccentricity values were increased from 90 to $120 \mathrm{~m}$ for the monopiles. As wind turbines are developed to capture wind energy, constructing taller structures will increase the output of each pile-tower and consequently the overall output of the wind farm. Figure 14 illustrates the lateral capacity of the circular structures embedded in both soil groups. It is clear that as the eccentricity values increase, the stiffness and the ultimate lateral capacity for both structures drop.

Table 7 compares the stiffness of the pile-tower structures embedded in both soil groups at a tower head displacement of $0.05 D_{\mathrm{p}}$ ( $D_{\mathrm{p}}=B=4.6 \mathrm{~m}$ for all structures). It is clear that the difference in the stiffness for each individual structure embedded in soil groups A and $\mathrm{B}$ significantly drops as the eccentricity values increase.

Table 8 illustrates the ultimate lateral capacities from the FE analysis with the methods adopted by Broms (1964) and Fleming et al. (2009) for the two pile configurations. The values were calculated for two nominated pile thicknesses.

From Tables 7 and 8, it is clear that the stiffness of the circular structure with an eccentricity value of $120 \mathrm{~m}$ can be enhanced by slightly increasing the pile-tower's thickness. For example, the difference in the stiffness at $0.23 \mathrm{~m}$ (Table 7) between the circular structure embedded in soil group A with a thickness of $60 \mathrm{~mm}$ 


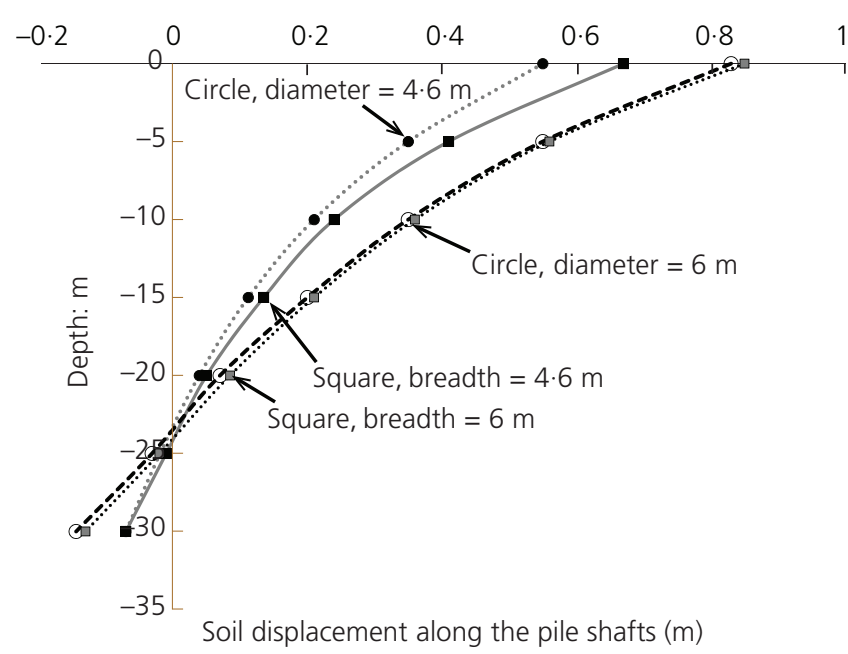

Figure 12. Soil displacements along the pile shaft for soil group A at the ultimate capacity

$(e=90 \mathrm{~m})$ and $95 \mathrm{~mm}(e=120 \mathrm{~m})$ is $+44 \cdot 82 \%$, while the ultimate lateral capacity of the taller structure $(e=120 \mathrm{~m})$ is standing higher (Table 8, 5.1 MN compared to $4 \cdot 5 \mathrm{MN}$ ). Furthermore, from Tables 7 and 8 , it is clear that by adopting a square structure, both the stiffness and the ultimate lateral capacity significantly improve when the eccentricity values increased, that is, comparing the results of the circular and square structures with an eccentricity value of 90 and $120 \mathrm{~m}$, respectively.
Figure 15 illustrates the results of the circular pile-towers embedded in soil group A for the changes made to the pile lengths. The methods adopted by Broms (1964) and Fleming et al. (2009) both consider the circular and square piles with a length of $10 \mathrm{~m}$ embedded in both soil groups to be short piles, that is, the soil failure controls the ultimate lateral capacities. Moreover, for the short piles $\left(L_{\mathrm{p}}=\right.$ $10 \mathrm{~m}$ ) embedded in the dense sand deposit (group B), the values calculated by the two methods are not equal. In contrast, a pile with a length of $20 \mathrm{~m}$ for both configurations embedded in soil groups $\mathrm{A}$ and $\mathrm{B}$ is still long for both methods; this meant that the pile structures control the ultimate capacities.

Table 9 illustrates the ultimate lateral capacities calculated by the FE analysis and the adopted methods. As discussed by Broms (1964), if the pile is long, the ultimate lateral capacity of the structure is not affected by increasing the pile length. In Figure 15, the ultimate lateral capacities of the 20,30 and $45 \mathrm{~m}$ pile lengths are equal $\left(M_{\max }>M_{\text {yield }}\right)$.

From Figure 15, it is clear that the stiffness of the $20 \mathrm{~m}$ circular pile embedded in soil group A is affected compared to the 30 and $45 \mathrm{~m}$ pile lengths. The change in the stiffness for the $20 \mathrm{~m}$ pile length can be attributed to the effective length $\left(L_{\mathrm{e}}\right)$ of the pile structure. This point can be investigated by Equation 1 . The value of $E_{\mathrm{s}}$ in Equation 1 can be considered as the average modulus of elasticity along the pile length (Meyerhof, 1995) or it can be equal to the soil modulus at the pile tip (Prasad and Chari, 1999). For a pile to be flexible with respect to its stiffness, the value of Equation $1\left(L_{\mathrm{e}}\right)$ must be less than the entire length of the pile $\left(L_{\mathrm{p}}>L_{\mathrm{e}}\right)$. In Equation 1, the equivalent

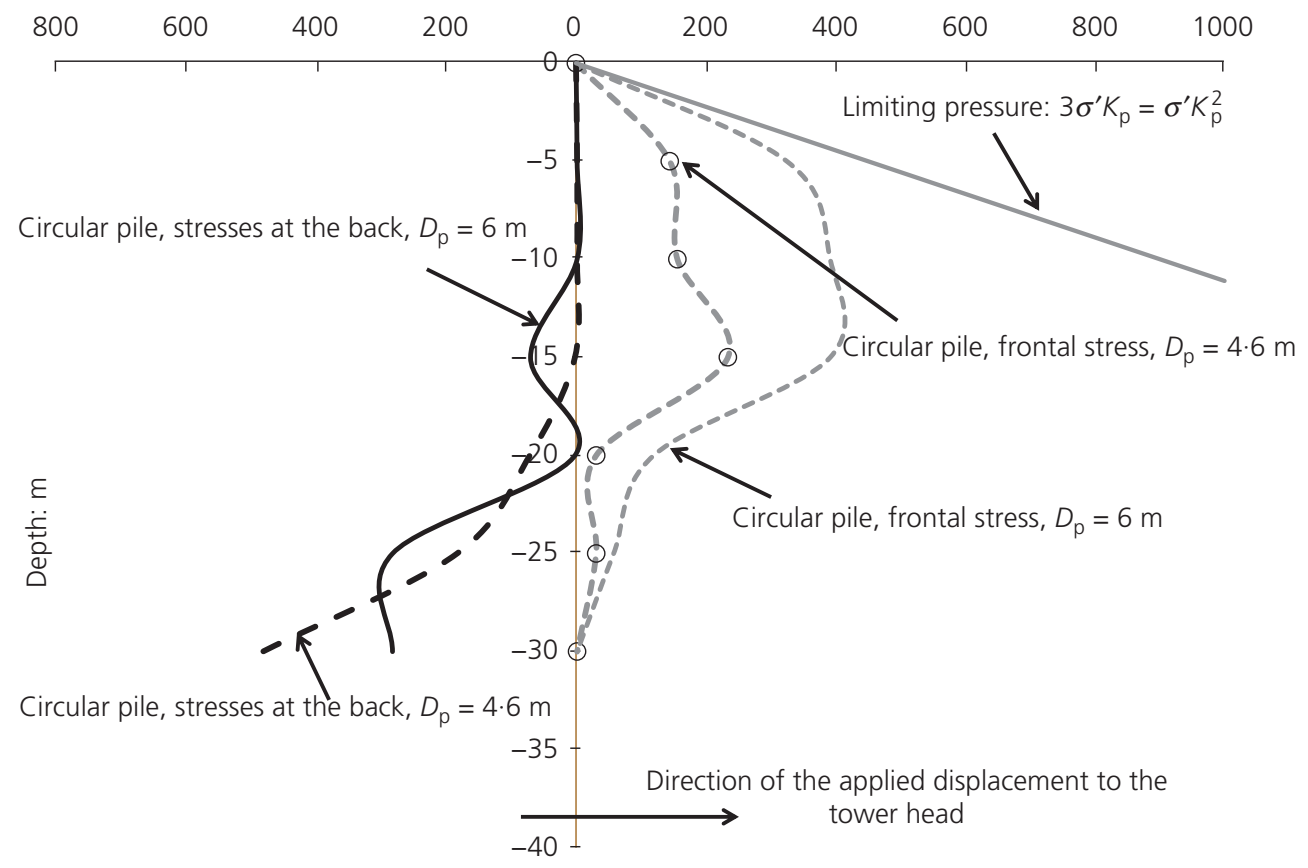

Soil stress along the pile shaft: $\mathrm{kPa}$

Figure 13. Lateral stresses imposed for different pile diameters at the ultimate lateral capacity (soil group A) 


\begin{tabular}{|c|c|c|c|c|c|c|c|c|c|}
\hline \multicolumn{5}{|c|}{ Circle $(t=60 \mathrm{~mm})$} & \multicolumn{5}{|c|}{ Square $(t=47 \mathrm{~mm})$} \\
\hline $\begin{array}{l}\text { Diameter: } \\
\text { m }\end{array}$ & $\begin{array}{c}\text { FE Group } \\
\text { A:MN }\end{array}$ & $\begin{array}{l}\text { Adopted }^{\text {a }} \\
\text { methods, } \\
\text { soil } \\
\text { Group } \\
\text { A:MN }\end{array}$ & $\begin{array}{c}\text { FE Group } \\
\text { B:MN }\end{array}$ & $\begin{array}{l}\text { Adopted }^{\text {a }} \\
\text { methods, } \\
\text { soil } \\
\text { Group } \\
\text { B:MN }\end{array}$ & $\begin{array}{c}\text { Breadth: } \\
\text { m }\end{array}$ & $\begin{array}{c}\text { FE Group } \\
\text { A: MN }\end{array}$ & $\begin{array}{l}\text { Adopted }^{\text {a }} \\
\text { methods, } \\
\text { soil } \\
\text { Group } \\
\text { A:MN }\end{array}$ & $\begin{array}{c}\text { FE Group } \\
\text { B:MN }\end{array}$ & $\begin{array}{c}\text { Adopted }^{\text {a }} \\
\text { methods, } \\
\text { soil } \\
\text { Group } \\
\text { B:MN }\end{array}$ \\
\hline 4.6 & $4 \cdot 5$ & $3 \cdot 6$ & $4 \cdot 5$ & $3 \cdot 6$ & $4 \cdot 6$ & $6 \cdot 1$ & 4.9 & $6 \cdot 1$ & $4 \cdot 9$ \\
\hline $5 \cdot 3$ & $6 \cdot 0$ & 4.9 & $6 \cdot 0$ & 4.9 & $5 \cdot 3$ & $8 \cdot 0$ & $6 \cdot 5$ & $8 \cdot 0$ & $6 \cdot 5$ \\
\hline 6 & $8 \cdot 0$ & $6 \cdot 3$ & 8.0 & $6 \cdot 3$ & 6 & $10 \cdot 2$ & $8 \cdot 4$ & $10 \cdot 2$ & $8 \cdot 4$ \\
\hline
\end{tabular}

a Methods adopted by Broms (1964) and Fleming et al. (2009) provide the same values

Table 6. The ultimate capacities for changes made to the piletower diameter and breadth

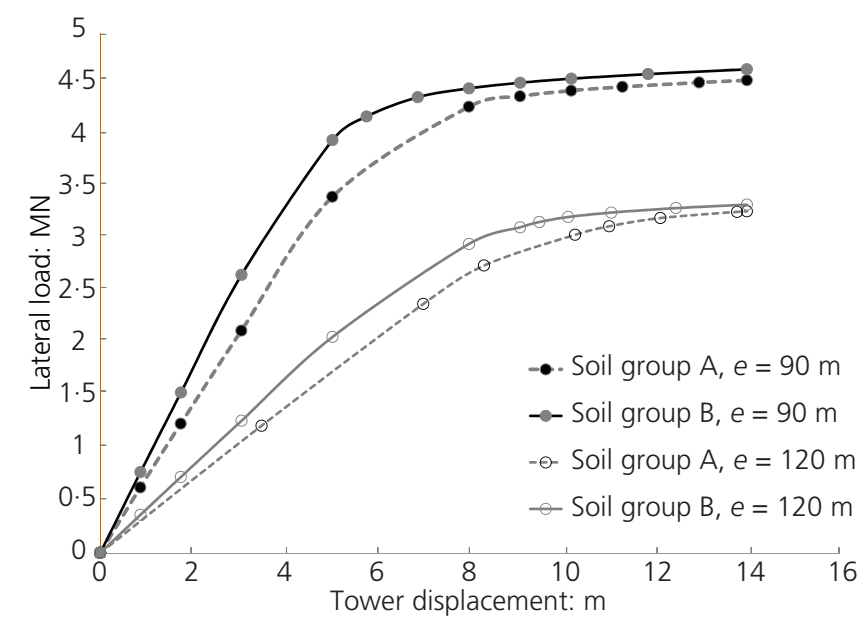

Figure 14. Changes made to the eccentricity (circular monopiles, $t=60 \mathrm{~mm})$ values of $E_{\mathrm{p}}$ will be used, as this equation is derived for a solid circular pile section and not for a hollow circular or square pile.

Equation 1 is adopted considering $E_{\mathrm{s}}$ (soil modulus) at the pile tip for both pile configurations embedded in soil groups A and B. The equation considers the $10 \mathrm{~m}$ piles embedded in both soil groups to be rigid with regard to their stiffness. In contrast, all 30 and $45 \mathrm{~m}$ pile lengths are considered as flexible piles for both soil groups, as illustrated in Figure 15 (worst-case scenario).

With respect to the $20 \mathrm{~m}$ pile lengths, Equation 1 predicts that both pile configurations must act as flexible structures when embedded in soil group B. Figure 16 illustrates the results of the square pile configuration with different pile lengths embedded in soil group B. It is evident that the $20 \mathrm{~m}$ square pile embedded in the stiff soil medium is acting as a flexible structure; this is also the case for the circular pile structure embedded in soil group B (not illustrated). In contrast, Equation 1 predicts that these structures $\left(L_{\mathrm{p}}=20 \mathrm{~m}\right)$
Circle $\left(D_{\mathrm{p}}=4.6 \mathrm{~m}\right)$

\begin{tabular}{|c|c|c|c|c|c|c|c|c|}
\hline \multirow[b]{2}{*}{ Eccentricity: m } & \multicolumn{2}{|c|}{ Group A: MN } & \multicolumn{2}{|c|}{ Group B:MN } & \multicolumn{2}{|c|}{ Group A: MN } & \multicolumn{2}{|c|}{ Group B:MN } \\
\hline & $t=60$ & $t=95$ & $t=60$ & $t=95$ & $t=47$ & $t=74.5$ & $t=47$ & $t=74.5$ \\
\hline 90 & $0 \cdot 17$ & 0.238 & $0 \cdot 21$ & $0 \cdot 305$ & $0 \cdot 24$ & $0 \cdot 32$ & 0.305 & 0.451 \\
\hline 120 & 0.08 & 0.12 & $0 \cdot 1$ & $0 \cdot 145$ & 0.115 & $0 \cdot 16$ & 0.15 & 0.22 \\
\hline $\begin{array}{l}\text { Difference due } \\
\text { to changes made } \\
\text { to eccentricity }\end{array}$ & $+112 \%$ & $+98 \cdot 3 \%$ & $+110 \%$ & $+110 \cdot 3 \%$ & $+108 \cdot 7 \%$ & $+100 \%$ & $+103 \cdot 3 \%$ & $+105 \%$ \\
\hline
\end{tabular}

$t=$ thickness $(\mathrm{mm})$ made to the eccentricity 


\begin{tabular}{|c|c|c|c|c|c|c|c|c|}
\hline \multicolumn{5}{|c|}{ Circle $\left(D_{p}=4.6 \mathrm{~m}\right)$} & \multicolumn{4}{|c|}{ Square $(B=4.6 \mathrm{~m})$} \\
\hline \multirow{3}{*}{ Eccentricity: m } & \multicolumn{4}{|c|}{ Group A: MN } & \multicolumn{4}{|c|}{ Group A: MN } \\
\hline & \multicolumn{2}{|c|}{ Thickness $=60 \mathrm{~mm}$} & \multicolumn{2}{|c|}{ Thickness = $95 \mathrm{~mm}$} & \multicolumn{2}{|c|}{ Thickness = $47 \mathrm{~mm}$} & \multicolumn{2}{|c|}{ Thickness $=74.5 \mathrm{~mm}$} \\
\hline & $\mathrm{FE}$ & $\begin{array}{l}\text { Adopted } \\
\text { method }^{a}\end{array}$ & $\mathrm{FE}$ & $\begin{array}{l}\text { Adopted } \\
\text { method }^{a}\end{array}$ & $\mathrm{FE}$ & $\begin{array}{l}\text { Adopted } \\
\text { method }^{a}\end{array}$ & $\mathrm{FE}$ & $\begin{array}{l}\text { Adopted } \\
\text { methoda }\end{array}$ \\
\hline 90 & $4 \cdot 5$ & $3 \cdot 6$ & $7 \cdot 0$ & $5 \cdot 6$ & $6 \cdot 1$ & $4 \cdot 6$ & $9 \cdot 4$ & $7 \cdot 6$ \\
\hline 120 & $3 \cdot 3$ & $2 \cdot 7$ & $5 \cdot 1$ & $4 \cdot 2$ & $4 \cdot 5$ & $3 \cdot 7$ & $6 \cdot 8$ & $5 \cdot 7$ \\
\hline \%Difference & $+36 \cdot 36$ & $+33 \cdot 33$ & $+37 \cdot 25$ & $+33 \cdot 33$ & $+35 \cdot 5$ & $+24 \cdot 32$ & $+38 \cdot 2$ & $+33 \cdot 33$ \\
\hline
\end{tabular}

${ }^{a}$ Methods adopted by Broms (1964) and Fleming et al. (2009) provide the same values

Table 8. Ultimate lateral capacities calculated for changes made to the eccentricity

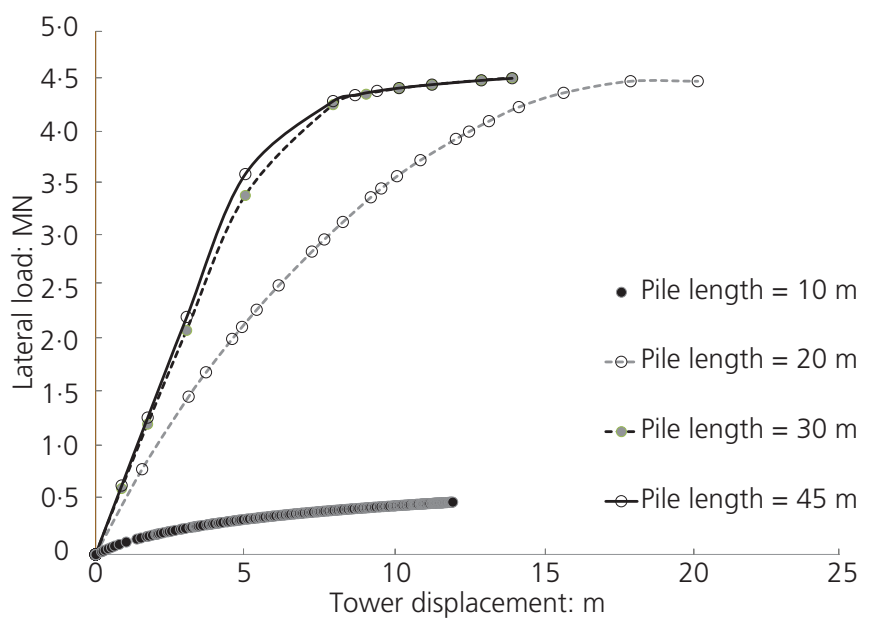

Figure 15. Changes made to the pile length for circular structures embedded in soil group A

would behave as rigid piles with respect to their stiffness when embedded in soil group A; this point is clear in Figure 15. This meant that the $20 \mathrm{~m}$ pile embedded in soil group A behaves as a long pile with respect to the criteria set by Broms (1964), while it acts as a short pile in regard to its stiffness. These dimensions were carefully adjusted so that the results would be in opposition to the tests conducted by Barton et al. (1983).

As previously discussed, the accuracy of the method adopted by Zhang et al. (2005) is illustrated at this point for the circular piletowers in Figure 15. To apply their method, the values of $\eta, \xi, K$ and $\delta$ can be defined from their charts to be equal to $0 \cdot 8,1 \cdot 0,1 \cdot 5 K_{0}$ and $0 \cdot 6 \phi^{\prime}$, respectively. The values of $K$ and $\delta$ are considered as average values from Tables 3 and 4 of their paper, respectively, that is, for pile-large displacement, driven $(K)$ and smooth steel $(\delta)$. For the 20,30 and $45 \mathrm{~m}$ pile lengths in Figure 15, the method adopted by Zhang et al. (2005) calculates the ultimate lateral capacities to be $1 \cdot 7,5 \cdot 5$ and $17 \cdot 5 \mathrm{MN}$, respectively. It was illustrated that for all three structures the ultimate lateral capacity was equal to $4 \cdot 5 \mathrm{MN}$. It is clear that the value of $17 \cdot 5 \mathrm{MN}$ predicted by Zhang et al. (2005) has a difference of $+288 \cdot 8 \%$ with the calculated result from the FE analysis and increases as the pile length rises.

\section{Conclusions}

Based on the results obtained in this investigation, the following conclusions can be made with respect to the behaviour of the monopile structures embedded in dense and loose sand deposits.

It is clear that the ultimate lateral capacity of wind turbines embedded in loose or dense sand deposits are controlled by their structural capacity and not by the soil failure. This meant that the changes made to the thickness, diameter or breadth, eccentricity and their constructive material can significantly influence the ultimate lateral capacities.

It is clear that the ultimate lateral capacities of the structures are not sensitive with respect to the soil properties. In contrast, the pile-tower stiffness is improved as the soil stiffness increases; this improvement can be up to $+46 \cdot 5 \%$ for a square pile-tower structure at a tower head deflection of $0 \cdot 23 \mathrm{~m}$.

It is evident that for all long piles ( $\left.M_{\max }>M_{\text {yield }}\right)$, square structures illustrate a significantly higher stiffness and ultimate lateral capacity compared to a circular structure with the same volume of material.

The soil displacements at the ultimate lateral capacities for a large diameter circular and square pile structure with an equivalent thickness are similar, but the square pile imposes slightly higher displacements on the soil for smaller pile diameters. The ultimate 


\begin{tabular}{|c|c|c|c|c|c|c|c|c|c|}
\hline \multicolumn{5}{|l|}{ Circle } & \multicolumn{5}{|c|}{ Square } \\
\hline $\begin{array}{l}\text { Length: } \\
\text { m }\end{array}$ & $\begin{array}{c}\text { FE Group } \\
\text { A: MN }\end{array}$ & $\begin{array}{l}\text { Adopted }^{\text {ad }} \\
\text { methods, } \\
\text { soil } \\
\text { Group } \\
\text { A: MN }\end{array}$ & $\begin{array}{c}\text { FE Group } \\
\text { B:MN }\end{array}$ & $\begin{array}{l}\text { Adopted } \\
\text { methods, } \\
\text { soil } \\
\text { Group } \\
\text { B:MN }\end{array}$ & $\begin{array}{l}\text { Length: } \\
\text { m }\end{array}$ & $\begin{array}{c}\text { FE Group } \\
\text { A:MN }\end{array}$ & $\begin{array}{c}\text { Adopted }^{\text {adhods, }} \\
\text { method } \\
\text { soil } \\
\text { Group } \\
\text { A:MN }\end{array}$ & $\begin{array}{c}\text { FE Group } \\
\text { B:MN }\end{array}$ & $\begin{array}{c}\text { Adopted } \\
\text { methods, } \\
\text { soil } \\
\text { Group } \\
\text { B:MN }\end{array}$ \\
\hline 10 & 0.5 & 0.69 & $1 \cdot 2$ & $\begin{aligned} \mathrm{Br} & =0.92 \\
\mathrm{Fl} & =1.23\end{aligned}$ & 10 & 0.5 & 0.69 & $1 \cdot 3$ & $\begin{aligned} \mathrm{Br} & =0.92 ; \\
\mathrm{Fl} & =1.23\end{aligned}$ \\
\hline 20 & $4 \cdot 5$ & $3 \cdot 6$ & $4 \cdot 5$ & 3.6 & 20 & $6 \cdot 1$ & 4.9 & $6 \cdot 1$ & 4.9 \\
\hline 30 & $4 \cdot 5$ & $3 \cdot 6$ & $4 \cdot 5$ & $3 \cdot 6$ & 30 & $6 \cdot 1$ & 4.9 & $6 \cdot 1$ & 4.9 \\
\hline 45 & $4 \cdot 5$ & $3 \cdot 6$ & $4 \cdot 5$ & $3 \cdot 6$ & 45 & $6 \cdot 1$ & 4.9 & $6 \cdot 1$ & 4.9 \\
\hline
\end{tabular}

a Methods adopted by Broms (1964) and Fleming et al. (2009) provide the same values; Br = Broms (1964); Fl = Fleming et al. (2009)

Table 9. Ultimate lateral capacities calculated for changes made to the pile lengths

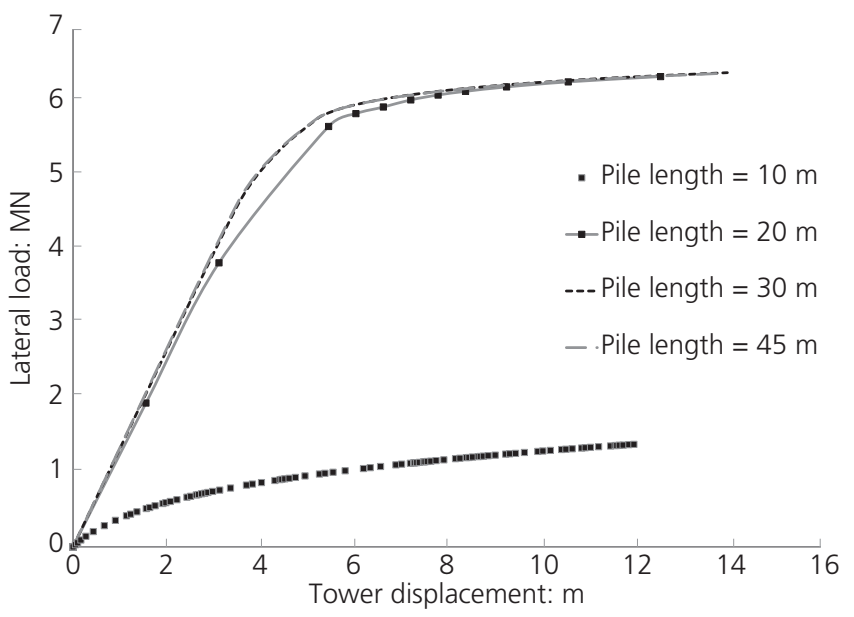

Figure 16. Changes made to the pile length for square structures embedded in soil group B

lateral stresses in front of the circular and square pile-tower configurations with equivalent dimensions embedded in the same soil group are similar for the region above the point of rotation. The latest points are for the centre of the circular and square pile cross-sections.

The methods adopted by Broms (1964) and Fleming et al. (2009) are well suited for calculating the ultimate lateral capacities of monopile structures embedded in loose and dense sand deposits. The results from the methods are conservative with respect to the FE results and are not sensitive towards changes made to the soil parameters, as in the case of the numerical results. Both methods are well suited for large pile diameters in the case of short piles ( $M_{\max }<M_{\text {yield }}$ ). It was illustrated that for high eccentricity values the ultimate lateral capacity calculated through the chart produced by Fleming et al. (2009) does not provide acceptable results.
Furthermore, it was demonstrated that the method adopted by Zhang et al. (2005) is not appropriate for long piles embedded in sand as they only consider the soil failure in their analysis.

From the bending moments generated on the structures, it is clear that a square pile-tower is capable of handling higher moments with respect to a circular structure. The methods of Broms (1964) and Fleming et al. (2009) can accurately calculate the location of the maximum bending moments for large pile diameters at the ultimate lateral capacities for both pile-tower configurations.

It is apparent that the equation generated for the effective length of the pile, which considers the stiffness, is conservative with respect to the criteria set by Broms (1964), that is, if the pile is flexible; it is likely to act as a long pile.

\section{Acknowledgements}

The author would like to thank The University of Western Australia for providing the opportunity to conduct this study.

\section{REFERENCES}

Atkinson J (2007) The Mechanics of Soils and Foundations, 2nd edn. Taylor and Francis Group, New York, NY, USA.

Barton YO, Finn WDL, Parry RHG and Towhata U (1983) Lateral pile response and p-y curves from centrifuge. In Proceedings of the 15th Annual Offshore Technology Conference, Houston, TX, USA, vol. 4502, pp. 503-508.

Bolton MD (1986) The strength and dilatancy of sands. Geotechnique 36(1): 65-78.

Broms BB (1964) Lateral resistance of piles in cohesionless soils. Journal of Soil Mechanics and Foundations Division 90(SM3): $123-156$.

Budhu M (2007) Soil Mechanics and Foundations, 2nd edn. John Wiley \& Sons, New York, NY, USA. 
Carter JP and Kulhawy FH (1992) Analysis of laterally loaded shafts in rock. Journal of Geotechnical Engineering 118(6): 839-854.

Cook RD, Malkus DS, Plesha ME and Witt RJ (2002) Concepts and Application of Finite Element Analysis, 4th edn. John Wiley \& Sons, New York, NY, USA.

Davies TG and Budhu M (1986) Nonlinear analysis of laterally loaded piles in heavily overconsolidated clays. Geotechnique 36(4): 527-538.

Fleming WGK, Weltman AJ, Randolph MF and Elson WK (2009) Piling Engineering, 3rd edn. Taylor and Francis, London, UK.

HKS (2006) ABAQUS Manual. V. 6.4, Hibbit, Karlsson and Sorensen, Inc., Pawtucket, RI, USA.

Jaky J (1944) The coefficient of earth pressure at rest. Journal for Society of Hungarian Architects and Engineers 78(22): 355-358.

Lehane BM, Pedram B, Doherty JA and Powrie W (2014) Improved performance of monopiles when combined with footings for tower foundation in sand. Journal of Geotechnical and Geoenvironmental Engineering 140(7): 04014027.

Logan DL, Chaudhry KK and Singh P (2011) A First Course in the Finite Element Method, 4th edn. Global Engineering, Stamford, CT, USA.

Malhotra S (2011) Selection, design and construction of offshore wind turbine foundations. In Wind Turbines (Al-Bahadly I. (ed.)). InTech, Rijeka, Croatia, http://dx.doi. org/10.5772/15461.

Meyerhof GG (1995) Behaviour of pile foundations under special loading conditions: 1994 R.M. Hardy keynote address. Canadian Journal of Geotechnical Engineering 32(2): 204-222.
Meyerhof GG, Mathur SK and Valsangkar AJ (1981) Lateral resistance and deflection of rigid walls and piles in layered soils. Canadian Journal of Geotechnical Engineering 18(2): $159-170$.

Meyerhof GG, Sastry VVRN and Yalcin AS (1988) Lateral resistance and deflection of flexible piles. Canadian Journal of Geotechnical Engineering 25(3): 511-522.

Poulos HG (1971) Behavior of laterally loaded piles: I-single piles. Journal of Soil Mechanics and Foundation Division 97(SM5): 711-731.

Poulos HG and Davis EH (1980) Pile Foundation Analysis and Design. John Wiley and Sons, New York, NY, USA.

Prasad YVSN and Chari TR (1999) Lateral capacity of model rigid piles in cohesionless soil. Journal of Soils and Foundation 39(2): 21-29.

Reese L and Van Impe WF (2011) Single Piles and Pile Groups Under Lateral Loading. Taylor and Francis Group, London, UK.

Ugural AC (2007) Mechanics of Materials. John Wiley and Sons, New York, NY, USA.

Ugural AC and Fenster SK (2003) Advanced Strength and Applied Elasticity, 4th edn. Pearson Education, New York, NY, USA.

Zhang L, Silva F and Grismala R (2005) Ultimate lateral resistance of piles in cohesionless soils. Journal of Geotechnical and Geoenvironmental Engineering 131(1): 78-83. 